Regions

THE VoICE OF THE MEMBERSHIP No 266 Summer 2007
THE NEWSLETTER OF THE

\begin{tabular}{|c|}
\hline Regional \\
\hline Studies \\
\hline Association \\
IHE INTERNATIONAL FORUM \\
FOR REGIONAL DEVELOPMENT \\
POLICY AND RESEARCH
\end{tabular}

Issn: 1367-3882

\title{
THE ROLE OF CULTURE IN THE ECONOMIC
}

DEVELOPMENT OF OLD INDUSTRIAL REGIONS

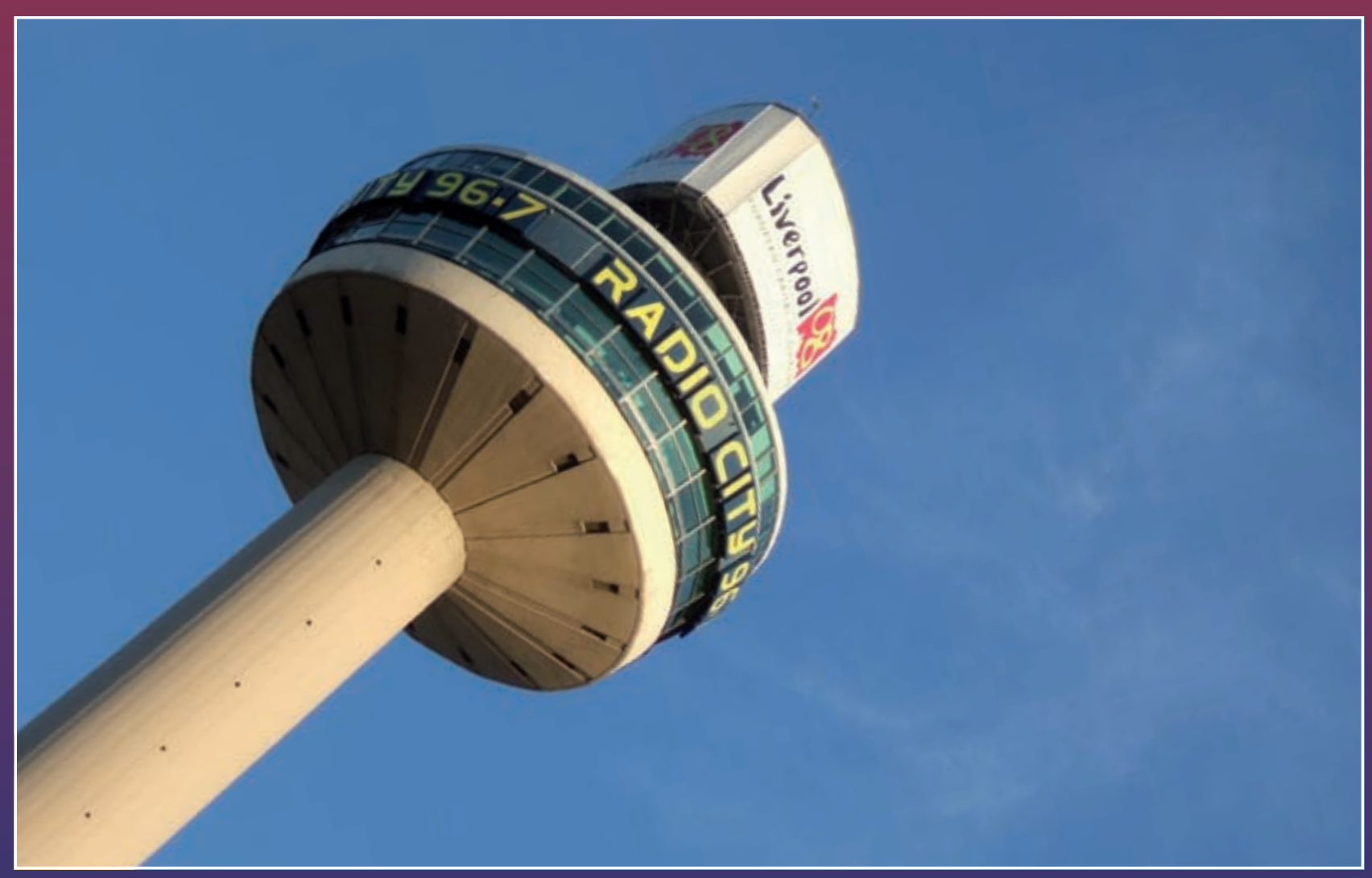

- Culture, clusters and the creative classes in the UK

- ICT, restructuring and Polish growth poles

- Tampere: from 'Manchester of the North' to 'more than Nokia' 


\section{Contents}

Comment \& Debate special: publicly funded research.. Ministers should read the research they commission

Policy challenges in building innovative city-regions

A word from the new Chair

In Depth. p6

Regional development in Iceland

Regional Survey p10

Culture \& regeneration in old

industrial regions

The creative classes in the UK

Cultural sub-clusters in Birmingham

Liverpool \& Manchester - dual city growth

Networks of cultural entrepreneurs

Rural cultural networks in the North East

Cultural industries in Tampere, Finland

ICT growth poles in Poland

Research Notes

FDI in Hungary

New Members.

News \& Reviews

p24

\section{Colophone}

\section{Editorial}

Paul Benneworth, Newcastle University;

Paul Braidford, Durham University;

Gert-Jan Hospers, University of Twente, the Netherlands.

Comment \& Debate

David Bailey, Birmingham University;

Danny Dorling, Sheffield University;

Richard Halkett, NESTA, London

$$
\text { In Depth }
$$

Elín Aradóttir, Impra Innovation Centre,

Iceland; Hjalti Jóhannesson, University of Akureyri Research Centre.

Regional Survey

Caroline Chapain, Birmingham University;

Nick Clifton, Cardiff University;

Roberta Comunian, Leeds University;

Phil Cooke, Cardiff University;

Laura Hampson, North West

Regional Development Agency;

John Harrison, Loughborough University;

Helen Johnson, Liverpool City Council;

Mariangela Lavanga, Amsterdam University,

Netherlands; Grzegorz Micek, Jagellonian

University, Cracow, Poland; Jon Swords, Newcastle University. Research Notes

Eva Kiss, Hungarian Aademy of Sciences. News \& Reviews

Gert-Jan Hospers, University of Twente, the Netherlands, Pavel Capik, University of Paisley,

John Harrison, Loughborough University. Cover photograph: Nathan Collins

\section{Contact Us}

Regions as you see it has changed - not only in appearance, but also in aim: towards that purpose, we are accepting submissions and suggestions for all three new sections, Comment \& Debate, the Regional Survey and News \& Reviews. To get in touch, email the editors at regions@ncl.ac.uk

\section{COMMENT \& DEBATE SPECIAL}

\section{The role of publicly-funded research}

We have now published six issues of the relaunched Regions, and you have hopefully become accustomed to its regular organisation. Having put you at your comfort with an expectation of what is to come, we now want to throw all that in the air. We have been trying to stimulate a debate about communications between policy-makers, practitioners and academics, and last

month, two brilliant opinion pieces were submitted to us. They are slightly longer than usual, but they really deserve to be published in full. We have decided therefore to restrain our comments this issue, and let these authors speak for themselves. Normal service will be resumed on page 6 !

Paul Benneworth, Paul Braidford \& Gert-Jan Hospers

\section{LEARNING THE HARD WAY}

\section{Danny Dorling argues policy-makers should learn from all their commissioned studies, not just cherry pick the convenient parts of the convenient ones.}

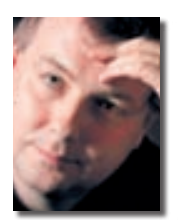

Government in Britain is still setting a bad example to the rest of the world in terms of the selectivity of its reporting and its summarising of its own commissioned research. This particularly affects the debate over regional inequalities and trends in them.

Writing in April 2007, I take the words of three government ministers. Currently their roles are as Secretary of State for the Environment (David Miliband); Minister of State for Housing and Planning (Yvette Cooper); and the Minister for Work (Jim Murphy). I pick on these three because they are not easy targets; indeed, they are those to whom we should be looking to make a difference to our cities and regions.

My worry is that a general concern that ministers have, to paint a rosy story, coupled with a spin they themselves receive from their key advisors, results in a general air of unreality and unsustainable comment continuously being made. This is engendering an environment where the real story of economic change - of some success alongside growing inequality - cannot be heard - a great loss to public debate.

At the very top of government, leaders are often cocooned from the world and find it very hard to understand their policies' unpopularity. But why, lower down in the government apparatus are junior Ministers also selectively quoting our research and statistics in an easily misunderstood way? Here is the first of my three examples. What the Minister said was the following:

'The State of the Cities' report was published just two or three weeks ago and it looked at the 56 primary urban areas of England, not just the eight biggest cities outside London, but the next forty-eight towns and cities, and it came to a stunning conclusion.

Twenty years ago, if we'd been having a conference about cities people would have talked about decline: about declining population; declining economies; declining public services. 'The State of the Cities' report - the most comprehensive analysis of Urban Britain for forty or fifty years - said that not only were our towns and cities getting better, not only were they getting better economically and socially faster than the national average, but that we had the best opportunity for a hundred years to make our towns and cities our leading towns and cities, not just good by British standards, but excellent in European terms.

David Miliband

What the data in the report showed was that some cities were becoming better-off and some not so better-off - and a gap was growing between them ${ }^{2}$. They were certainly not all getting 'better economically and socially' than the national average, as the quote above implies. Nor were they amounting to be excellent in European terms. I know because I worked with a group of research to pull together some of the data for the report. The way the data is represented in the comments is not untrue, but it is clearly at the margins of how the data could be interpreted. The issue for me arises because this is not just an isolated example, but is part of a more worrying trend. 
Here's another illustration, dealing with a more local issue coming from a statement made by another minister almost a year ago. The press release was highly optimistic:

The transformation of many of our coalfield areas has been dramatic. When the pits were closed many coalfield communities saw soaring unemployment and their communities were devastated. Now, thanks to coalfield regeneration, the jobs are coming back.

Many former miners have had training to get new jobs and whole communities are being revived. On some of the pit sites we are even seeing more jobs above ground then there were below when the pits were open....

Yvette Cooper ${ }^{3}$

This squares rather awkwardly with the underlying research, which was more sanguine about the prospects of the residents of these places.

The growth in replacement jobs in the coalfields that was evident before 1998 continued over the next five years but at a slower pace than in non-coalfield areas. Moreover, despite some relative improvements, the deprivation, health, educational qualifications and enterprise 'deficits' in the coalfields persisted as a long-term legacy from the loss of mining employment (see paragraphs 31-33). These deficits hampered and will continue to hamper the capacity of residents to benefit from any increased job opportunities that come their way.

Source: Para 24 of 'Regenerating the English Coalfields,

So why do Ministers feel the need to tell the most positive version of the story justified by the facts? The blame - in the UK at least - does not lie solely with Ministers, but also in the very divisive public discourse which hinges on 'all or nothing' stories, with no room for the more nuanced story that is the tale of inequality in the UK.

Put simply, the worry is that if Ministers are not so optimistic, then their message will not be heard. Writing on Friday March 9th the Minister for Work, Jim Murphy, 'blogged' a message quite far from the usual carefully crafted spin:

Into the valleys

I was visiting the Welsh valleys today to discuss how we can get more people into work. My colleagues, John Hutton, Anne McGuire, James Plaskitt and Lord McKenzie of Luton have also covered a fair few miles between them from Cardiff and Swansea to North Wales and Usk. Wales is a classic example of the success we've had in getting more people into work - there are over 130,000 more people in work and whilst cities like Cardiff have been transformed, there are still parts of the country where a life on benefits is still the norm.

This leads us to a number of questions: Why do less people find work in the valleys than in the rest of Wales? Why are you more likely to get a job in the Cynon Valley, for example, than in Merthyr Tydfil? How can we help 20 thousand more people off Incapacity Benefit and into work? Chatting to local MPs, employers and other people on the ground has given me a much better appreciation of the issues.

So what's the answer? This is probably going to sound like a typical politician's response but I believe there isn't one, single answer. There are many. What's important is making sure local areas combine the support of different organisations, private and voluntary, to best effect. We'll be on the right path when a lone parent in the valleys doesn't have to worry about who's looking after the kids or if they have the right skills for a job because they know all the back-up they need has already been sorted out in the first place.

Source: Jim Murphy's blog ${ }^{5}$
So what thanks did Jim get for admitting this difficult message? Comments to his blog are vetted by civil servants - despite that, they let this comment through, which illustrates that Ministers cannot win with criticism from whatever angle!

\section{Robert wrote:}

And then you woke up at home with your family and said love I had a nice dream I made Wales a nice place to live with lots of jobs and the sick and disabled rose up and walked.

\#2 - Posted on 13-Mar-07 at 8:46am.

Damned if they dream, damned if they spin, damned if they are honest, damned when they lie. It is hardly surprising that few of those at the top of numerous policy ladders feel it is worth trying to admit the story of their policies' partial success.

We need our Ministers to be taking the lead in explaining this reality as a precursor for genuinely trying to make a difference, and to set the tone for a new - more reflective - public discourse. So here is my advice for these Ministers.

Before you try to find the answer, or suggest that there are a plethora of answers, you need to accept the reality that we as a nation are still becoming more unequal: individually, by community, by city and by region.

Read the research reports you commission, and not just the two page summaries that your officials hand you as your limousine speeds off for that visit to the regions!

\section{Box 1 The UK's mixed picture of economic inequality}

The actual story of economic inequalities is revealed in statistics which receive very little coverage in government reports, or in Ministerial pronouncements. Buried in the press release (15th December 2006) for the latest estimates of regional Gross Value Added you find that:

Shares of GVA: London (17.0 per cent) and the South East (15.6 per cent) had the largest share of total UK GVA in 2005. London's and the South East's share of UK GVA has increased since 1995 when it accounted for 15.2 per cent and 14.9 per cent respectively. Northern Ireland (2.3 per cent) and the North East (3.4 per cent) had the smallest share of UK GVA in 2005.

True, there are great problems with government's regional accounts, but that is not reason to ignore them (for an entertaining story of the receipt of personal abuse and the complete mess that is regional statistics, read the words of the then National Statistician Len Cook) ${ }^{7}$.

Our cities are becoming more unequal both within and between them. Outside our cities our coalfields are not catching up with the average, let alone the affluent areas which they moved even further away from so rapidly all those years ago in 1984/85. Our regions are slowly pulling apart; and our countries are less and less united in common experience. 
Danny Dorling is Professor of Human Geography at the University of Sheffield.

1. Speaking on 3rd of April 2006 as then-Minister of Communities and Local Government, Presentation for 'The Work Foundation': http://www.theworkfoundation.com/ Assets/pdfs/Ideopolis_DavidMilibandspeech.pdf

2. For more details and a summary table showing how each of the 56 cities actually fared see: http://sasi.group.shef.ac.uk/publications/ 2006/dorling_inequalityinBritain1997_corrected.pdf

3. From press release DCLG 22/3/2007 'Coalfields discover they have a second life', quote: Housing Minister, Yvette Cooper, 22nd March 2007. http://www.communities.gov.uk/index. asp?id $=1002882 \&$ Press NoticeID $=2382$

4. Extract taken from executive summary of the report the minister was referring to 'Regenerating the English Coalfields' - interim evaluation of the coalfield regeneration programmes, published by DCLG: http://www.communities.gov.uk/pub/894/InterimEvaluation ofthecoalfields regenerationprogrammes_id1508894.pdf

5. Taken from Jim Murphy's blog [5] http://www.dwp.gov. uk/welfarereform/blog/index.php/page/2/

6. Available on-line at http://www.statistics.gov.uk/pdfdir/ gva1206.pdf

7. Available on-line at http://www.publications.parliament.uk/ pa/cm200102/cmselect/cmtreasy/1289/2103009.htm

\section{THE INNOVATION POLICY CHALLENGE}

\section{Richard Halkett argues that the future lies with building innovative city-regions}

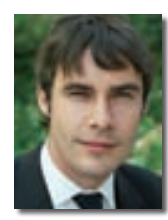

Last October, the UK's National Endowment for Science, Technology and the Arts (NESTA) launched a major research report entitled 'The Innovation Gap: why policy needs to reflect the reality of innovation in the UK'. This argued that the metrics currently used to measure innovation (patents, R\&D spend and the like) were heavily biased towards traditional scientific and technical innovation, and against the types of innovation that were most relevant to an increasingly service-based economy like the UK. Because policy tends to follow measurement, innovation policy was likewise skewed (we define innovation as 'the successful application of new ideas').

However, as we began to develop 'The Innovation Gap' into a strand of research called 'Hidden Innovation', it became apparent that much as one size did not fit all sectors, one size did not fit all regions: if we thought about innovation more broadly, so we had to consider skills, culture, governance and the full 'ecology of innovation'. This is particularly important in the UK where the development of the devolved administrations in Scotland and Wales and the increasing emphasis on regions (through RDAs) and cities (through Science Cities and other initiatives) means that economic policy is increasingly decided at a sub-UK level.

\section{One size does not fit all innovation}

As a result, we launched three research partnerships and one major initiative. We are working with the Centre for Cities (previously part of the IPPR) to uncover the unique aspects of the urban innovation system and the policy devices that can be used to stimulate it. We are working with CURDS (Newcastle University) on the best forms of regional leadership for innovation at different stages of a region's development. And we are working with James Simmie (Oxford Brookes University) and Ron Martin (Cambridge University) on a project to analyse the relationships between path dependence, territorial innovation systems and absorptive capacity in determining the abilities of city regional economies to adapt in response to changes in their economic environments.

In addition to these, NESTA has launched its Innovation Policy \& Research Fellows programme. These one-year funded posts will be for up to 12 regionally-based fellows to work on regionally-focused innovation policy issues which have the potential for UK-wide resonance. They are also to be co-managed by a partnership between an academic institution and a policy or business entity. Their aim is not only drive forward research into innovation but also build the next generation of innovation researchers and directly foster links between the academic and policy communities.

As we move forward with this agenda, a number of issues stand out, several of which were explored in our policy briefing, 'Innovation in UK Cities'.

The first is the centrality of cities and regions to the UK's innovative potential. Thomas Friedman contests that the 'world is flat'; by contrast, when you look at where innovation happens, Richard Florida has observed that 'the world is spiky'. These aren't contradictory - the answer lies in the increasingly importance of locality in an internationalising world economy: developing and exploiting high-value ideas requires far more than access to the kind of knowledge that can be codified in copyright and patents, and transmitted easily over the internet.

Increasingly, the differentiating factor is 'sticky' (tacit) knowledge - the 'knowhow' rather than 'know-what'. This can only be gained or transmitted through personal experience and interactions. Since innovation is a 'contact sport', cities (embedded in supporting regions) form important nodes in national and international innovation networks within which tacit knowledge is diffused.

\section{The city as an arena for the innovation game}

This, however, presents a policy problem: strong cities with highly skilled populations and good infrastructures attract large companies that in turn attract highly-skilled people and generate wealth for the local economy: a virtuous circle. There is clearly also the potential for a downward spiral for those cities that do not start out on the right track or in the right environment. The challenge is how and when to break the cycle.

A further, largely political, challenge, now facing UK regions, is city/ region tension, frequently more than a little related to ego and turf wars, but there is a real problem there too. Core cities have the density of population to generate ideas and revenues, the infrastructure to bring in new people and ideas, and the institutions and governance structures to hold them there. Rural areas have none of these things.

As the UK's cities strive to compete in a global market, the temptation is for them to look increasingly to themselves to become more excellent at the expense of all other priorities, to neglect the wider regions within which they are embedded. 
This is in no one's interests, neither regional development agencies nor the national government: the challenge of tying urban excellence to the wider region is one that must be confronted, and confronted fast.

\section{Towards regional support for local innovation}

Interest in sub-national innovation has emerged just as conceptions of innovation have taken a new and more complex turn. Traditionally, innovation strategies have been based upon a linear understanding of innovation, where research and development in university or business laboratories generates a stream of inventions that are then commercialised. This view has the advantage of clear and well-tried policy interventions, such as building technology parks and incubators, supporting university-industry technology transfer or raising local venture funds.

However, for some time now, innovation has been understood as a multi-directional and iterative process that involves multiple actors - an ecology rather than a pipeline. While this has improved our understanding of the process of innovation, it has given policymakers a headache. Stimulating an ecology of innovation requires precise interventions across diverse policy areas, including education and skills, business support, and infrastructure, as well as technology transfer and more traditional interventions.

Finally, the UK seems to have an inadequate appreciation of the importance of the different contexts in which cities find themselves. Cities and the regions in which they sit can be categorised in many different ways. They might exist in polycentric or uni-centric regions; they may depend on services, engineering or tourism; they might be home to a large population of multinationals or alternatively be based upon a high proportion of SMEs.

This under-appreciation of difference is not simply a national policy problem: it is mirrored at the city or regional level. Perversely, a notable characteristic of many regional and city innovation strategies is their similarity. Of England's nine regional innovation or economic strategies, eight include biotechnology or health sciences as a priority area, and five mention the creative industries.

Nearly all include traditional sciencebased policy interventions such as technology parks, and university-industry collaboration. This similarity of approaches inevitably leads to competition. But it is not clear exactly how many biotechnology hubs the UK really needs or can sustain, and this duplicative approach may waste resources. The number of competing efforts may also be counterproductive preventing the formation of critical mass at any one location.

What the UK requires is sufficient competition between local areas to allow for local relevance, policy experimentation and the emergence of good ideas, but not so much competition as to be destructive to the nation's overall ambitions or its use of public resources. Centralised control would stifle local experimentation rather than support it. Successful local innovation strategies require in-depth knowledge of local issues and capabilities, which are difficult to appreciate at a national level.

Instead, local ambitions should be placed in a regional and national context. In developing their innovation strategies, cities should conduct the policy equivalent of an environmental assessment to establish their own strengths and understand what others are doing. The resultant strategy should overtly complement those efforts rather than compete against them.

It is beyond question that the UK's city regions will form the focus of an innovation-based economy, and are therefore critical to its future international competitiveness. The challenge is two-fold: how to accelerate the leaders and how to bring up the laggards. The policy world tends to constantly look overseas for formulas for success. But uncovering the antecedents of success retrospectively is easy; identifying the components in advance is not. Unfortunately, only the latter is useful.

The UK needs to learn a little from elsewhere as to where to look, but it then needs to apply its best minds and most experienced people to the problem of uncovering the challenges and opportunities presented by its unique circumstances. Only then will it maximise its chances of success in the global economy, and only then will innovation policy and research begin to earn its keep.

Richard Halkett is the Research Director of NESTA, the National Endowment for Science, Technology and the Arts. NESTA is the largest single endowment in the UK, and is devoted exclusively to fostering innovation. The cited research is available online, in the 'Research' area of the NESTA website. For further information, please see http://www.nesta.org.uk/.

\section{Chief Executive's} Report

Our Chief Executive, Sally Hardy, is currently on study leave improving her language skills, so I'm standing in to pen a few words in her place. Sally's study leave is long-overdue and much deserved given all she done to ensure the continued development and success of the Association.

Our Working Group scheme has just been relaunched and members are encouraged to apply for up to $£, 3000$ (around $€ 4500$ ) to run a series of events (up to three over two years). The next round of funding will be decided on 29th June: members are encouraged to submit bids for funding by 9 th June. Full details can be found on our website.

Our recent International Conference, held at the Universidade de Lisboa in early April in Lisbon, was a great success. Over 300 academics, policy-makers and practitioners met to exchange ideas, network and enjoy socialising in a wonderful location. Fascinating plenary and parallel sessions provided many opportunities to discuss key regional issues.

As usual, the conference organisation was seamlessly efficient: delegates commented on how welcoming and friendly the event was. Special thanks go to Mario Vale (Conference Organiser) and the RSA team of Lisa, Frankie and Lizzie for making it such a success.

We're delighted to say that the next International Conference will be in Prague in the early summer of 2008. We hope to see you there.

Between now and then we also have our summer Student Conference and our Winter Conference on 'Transport and Regional Development'. Details will soon be available on our website.

We continue to work hard to develop and grow the Association. We are finalising a new development plan to set strategic objectives until 2010. We would very much welcome your ideas and input on developing the Association in the future and look forward to hearing from you.

David Bailey Chair 


\section{REGIONAL DEVELOPMENT IN ICELAND}

\section{An overview of recent trends and key policy responses}

\section{INTRODUCTION}

Iceland is Europe's most sparsely populated country with approximately three inhabitants per $\mathrm{km}^{2}$. The interior of the country is to a large extent uninhabitable, consisting of barren highlands, lava fields, glaciers, and mountains. The population is mostly concentrated in a narrow coastal belt and in valleys extending from the coast. The total population of Iceland is just over 300,000, of which over 63\% lives in the capital city (Reykjavík) and seven surrounding municipalities (together generally referred to as the capital region).

The remaining $37 \%$, or roughly 112,000 people, live in towns along the coast, other small urban centres, as well as in sparsely populated farming communities (Statistics Iceland, 2007). Together these are referred to as landsbyggdin in Icelandic, as a synonym for all areas outside the capital region. According to a definition of a functional urban area (FUA), as defined by the EU Espon programme, $75 \%$ of the Icelandic nation live within a 45 minutes driving distance from Reykjavík.

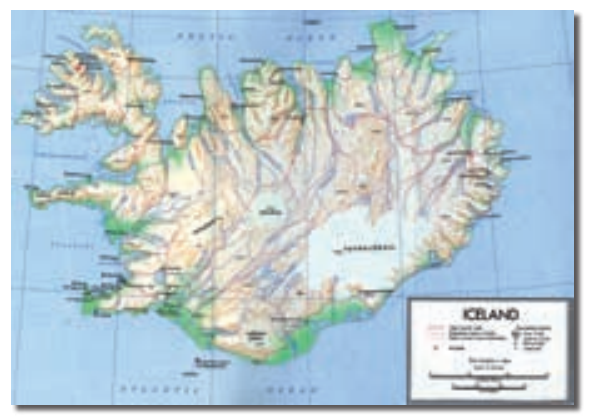

Iceland has a strong economy with low unemployment and a high standard of living. The rich fishing banks around the island as well as the abundant hydro and geothermal power are Iceland's most valuable natural resources. The economy depends heavily on the fishing industry and marine products constituted 56.7\% of Iceland's income from exporting of commodities in the year 2005. Another important industry is the aluminium industry, which accounted for close to $18.5 \%$ of the income from export of commodities in the year 2005 .

Tourism is also an important industry and a rapidly growing source of foreign currency. (Statistic Iceland, 2007). The fastest growing sectors are, however, various service sectors including financial services. Some high-tech industries such

Iceland is a country of merely 300,000 people, yet it is regularly placing among the top European nation states in international rankings for competitiveness as well as for entrepreneurial activity. Iceland is, however, a country of considerable regional differences, with a strong and growing core around the capital city, but also a number of challenged rural regions. This article gives an overview of regional development in Iceland, key challenges of peripheral regions and recent policy responses. Elín Aradóttir, Impra Innovation Centre \& Hjalti Jóhannesson, The Research Centre of the University of Akureyri

as ICT and pharmaceutical industries have furthermore gained considerable ground in recent years. A considerable proportion of the activity within these new sectors takes place in branches located abroad.

According to the World Competitiveness Yearbook 2006, Iceland ranked 4th consecutively in 2005 and 2006 and the country scores generally high according to indicators such as education, R\&D, innovation and economic performance, used by Eurostat to measure competitiveness. According to the Global Entrepreneurship Monitor (GEM) the prevalence of entrepreneurial activity in Iceland in 2005 was higher than in most other countries in the world. It is slightly higher than for the high-income countries on the whole, substantially higher than in the Nordic countries (except for Norway) and comparable to the United States (Sæmundsson and Baldursdóttir, 2006, p. 10).

Employment by industry sectors in Iceland has changed in accordance with the development of other industrialized societies. Technological advancements have led to a decrease of employment in the more traditional sectors such as agriculture, fisheries and fish processing, while employment in various services, has expanded. In 2005 close to $72 \%$ of the Icelandic workforce were employed in various services, while agriculture, the fisheries and fish processing altogether accounted for just under 10\% (Statistic Iceland, 2007). Employment in agriculture, fisheries, and fish processing in many communities outside the capital area is nevertheless still fairly high. The most recent available numbers for the regional level for example show that $36 \%$ of the labour force in the Westfjords region work in these sectors and 25\% in the Northwest region (Statistics Iceland, 2003).

\section{The delivery of regional} policy and planning and recent policy responses

Iceland has two government levels, the central state and 79 municipalities. There is thus no intermediate county level in Iceland. It is primarily the state government which has the responsibility to carry out the official rural development policy for Iceland but the municipalities are important actors in this area e.g. by working in the interest of their inhabitants and businesses by lobbying the Parliament and the government and through joint projects with various governmental agencies. In the case of Iceland, it is important to point out that the national rural policy and regional development policy are presented as one policy initiative. Hereafter this will be referred to as rural development policy.

\section{Rural Policy at the National \\ Level}

Since the mid 1960s numerous rural development plans for individual regions have been carried out. However, in 1991 there was a change of state government and in the same time a considerably different approach towards rural development emerged. A governmental policy, which was passed in 1991, stated 'the government will by general measures support efforts to strengthen manufacturing and services in the growth regions in 'landsbyggdin' [rural Iceland] and facilitate adjustment to a changing economy and market conditions'. (Ríkisstjórn Sjálfstæðisflokks og Alpýðuflokks, 1991, p. 10). Much structural change took place in the following years of the early 1990s and many jobs, especially in manufacturing were lost while new ones were created, especially in various services. The society was on a fast lane towards the service based economy and becoming more urbanized than ever before. 
Prior to 1999 the responsibility for rural affairs lay with the Prime Minister. A new Act on the Institute of Regional Development in Iceland (no. 106/1999) moved the responsibility of rural development to the Minister of Industry and Commerce. This took effect on January 1st 2000. This can be seen as an important change of course with rural development policy being changed to more specific actions instead of being a more general cross sectoral national policy (Valsson, 2002).

Four rural development plans in the form of parliamentary resolutions have been passed by the Parliament since they were initiated in the early 1990s. In all these plans some emphasis is put on strengthening so-called growth regions (Jóhannesson, 2006 and Eðvarðsson, 1998). However, in the two first plans an actual definition of which regions would be categorized as possible growth regions was not put forward. The third plan, i.e. for the period of 2002-2005, marked a difference. A specific growth region was identified, namely Eyjafjörður in North Iceland, being the most populous region outside the capital region. The proposal to the parliamentary resolution included five main objectives, 12 fields of importance were identified and finally 22 specific measures. Specific ministries and the Institute of Regional Development should be responsible for carrying out these measures. Finally, a special project management group was to be established to supervise the implementation.

\section{Policy Initiatives - Regional Level}

Currently there is no mandatory requirement for municipalities or regions of Iceland to form a specific policy or a plan for economic and/or social development (Nordic Innovation Centre, 2005). In this context it is important to reaffirm that Icelandic government structure has only two official administration levels, the state level and the municipal level. The term region in Iceland, therefore, does not represent an official governmental level, with associated governmental structures, income and expenditure basis, or responsibilities. Box 2 summarises the actors which have an influence on Icelandic regional development policy.

Partly due to these circumstances, policy making, in a traditional sense, is fairly weak at the regional level. However, so-called growth agreements, which have been made parallel to the implementation of the rural policy for
2002-2005, can be regarded as important in this context. The agreements are a form of regional planning for economic development with a focus on certain economic sectors. They have the broad mandate to increase the competitiveness of regions and increase economic growth. The agreements have been made between the state government and actors in selected regions and are based on a cluster ideology. The current rural policy for the period 2006-2009 states that similar growth agreements will be made in that period for most other regions.

\section{Discussion: key challenges of rural regions}

Although the previous section reflects a positive picture of the Icelandic economy, Iceland is a country of considerable regional differences. These differences are evident when looking at migration patterns, the development of local

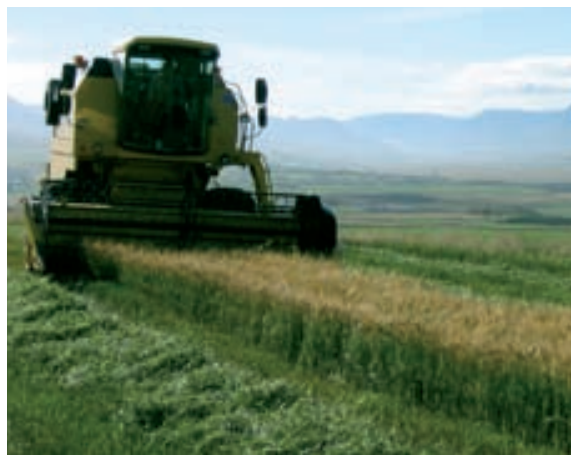

A barley field in Eyjafjörður in North Iceland

Most areas of Iceland, apart from the capital region, have experienced considerable out-migration in the last few decades. The highest out-migration numbers are seen in Westfjords region (about 24\% of the population in the period 1980-2002) and in the North West and East regions (a decrease between 9\% and 13\%). Respectively the population of the capital economies and labour market issues.

\section{Box 1: The Parliamentary framework for Icelandic regional planning}

The resolution for regional development in Iceland which is currently valid was passed by the Parliament in the spring of 2006. This policy follows a similar planning procedure as for the previous period. It has three main objectives. As can be seen below these objectives have a fairly broad scope:

a) To strengthen specific regional centres but at the same time find ways to strengthen settlement in locations where population has been shrinking.

b) To assist communities in rural Iceland to adapt to rapid social development and change in the economy.

c) To strengthen the economy, education, culture and social equality in 'landsbyggdin'.

Specific emphasis is put on the importance of education and culture, increased innovation and economic development, improved transportation and communications and strengthening of the regional centres of Akureyri (in north Iceland), Ísafjörður (in the Westfjords) and central east Iceland and other important economic and service centres of the country.

During the planning period, the government shall put emphasis on three main topics:

a) To greatly increase availability of education in 'landsbyggdin'

b) To increase the number of jobs in public service in 'landsbyggdin'.

c) To strengthen the Institute of Regional Development by increasing its budget and make it possible for the institute to carry out its tasks in the field of rural development.

The three main objectives were developed into 23 specific measures in order to meet the objectives of the policy. These measures specifically aim at harmonization between the rural development policy and other national policies and official measures of the government. In many cases the measures aim at strengthening the activity of the public sector in 'landsbyggdin'. The policy includes limited details for the actual implementation of each measure (actors responsible, financial plans, etc.), but states that the Minister of Industry and Commerce shall assemble a project management group to supervise the implementation of the rural development policy.

It is important to stress that the Icelandic national policy for rural and regional development is in the form of a parliamentary resolution which is not legally binding and can be shunned without penalties. Therefore, much determination and concerted effort by the various actors is needed to implement the policy. 
region has grown considerably in the same period, or around 50\% (Statistics Iceland, 1997 and Statistics Iceland, 2003). The migration patterns have also resulted in uneven age and gender balance between regions. Thus males and older people are overrepresented in many rural regions.

The migration trends are also related to employment levels. Although generally speaking the Icelandic labour market offers abundant work for all Icelanders and some sectors even rely to a considerable extent on foreign workers, a high out-migration rate seems to tend to have positive effects on the official unemployment rate. Many people seem to opt to migrate from rural areas instead of accepting unemployment benefits. It is a well-known fact that the level of diversity of local labour markets heavily influences migration to and from each locality. This indicates that the official labour market statistics should be approached with care when describing the employment situation of rural localities in Iceland. Wage levels are generally higher in the capital region than in other regions. In 2005 the average net income per capita was around $15 \%$ lower in regions outside the capital region (Statistics Iceland. 2007).

A recent study shows that in the period of 1998-2004 there were considerable regional differences in economic growth (Institute of Regional Development in Iceland et al 2007). In this period the capital region experienced 39\% growth while the national average is $29 \%$ and the rate for other regions spans from $-6 \%$ (the Northwest region and the Westfjord region) to $22 \%$ (the West region).

The economy of regions outside the capital is less diverse than that of the capital region. The growth sectors of rural areas are quite different from those in the capital region. These include tourism, fish farming, and in the eastern part, aluminum production drawing on abundant geothermal power resources will soon become an important addition to the economy.

Growth in sectors such as financial services and ICT, primarily takes place in the capital region. The operation of universities and other institutes of higher education have become an important addition to the economy in a few places in Iceland outside the capital region. This is most notable in the town of Akureyri in the north but also in the West region. Educational centres focusing on higher education and distance learning are very much looked upon as an important addition to local economies.

Finally it should be noted that the data gathering behind Icelandic results in international comparison studies, such as indicators on education, $\mathrm{R} \& \mathrm{D}$, innovation and economic performance, seldom give much information on regional differences in Iceland. Such results could generally be regarded as heavily influenced by results for the selected variables in the capital region where economic activity, innovation and public expenditure is most concentrated.

This being said it is also important to note that the overall status of localities outside the capital region varies considerably, not only between regions but also within regions.

\section{Box 2: Policy Implementation - the Key Actors}

The actors that could be regarded as having the most influential role in implementing regional development policy through direct developmental programmes and project are the following:

The Institute of Regional Development in Iceland [In Icelandic: Byggðastofnun] is a state run institution under the authority of the Minister of Industry and Commerce. According to Act 106/1999 the institute's main objective is to strengthen settlement and economic activity in regions outside the capital region. To fulfil this objective the institute shall prepare, plan and finance projects and provide loans with the purpose of strengthening settlement, economy and enhancing innovation. Preparing a proposal of the rural development policy for Iceland is one of these tasks. Secondly, the institute shall monitor the settlement in the country by collecting data and carrying out research. The institute cooperates with and supports financially economic development corporations in regions outside the capital region. In order to strengthen settlement and economic activity in rural areas the institute can carry out plans to strengthen settlement and economy in specific regions.

Impra - Innovation Centre [In Icelandic: Impra nýsköpunarmiðstöð] is operated as a department within IceTec (Technological Institute of Iceland). Impra's role is to assist entrepreneurs in evaluating business ideas, provide counselling with start-up, growth, and management of companies, and be a link in the communication chain between individuals, companies and public agencies. Experts at Impra also advise SMEs on how to improve their business productivity, encourage innovation and assist in export planning, for example, by facilitating cooperation in R\&D and technology transfer with foreign businesses. Impra, furthermore, aims at establishing formal cooperation between organizations that provide support for economic development in Iceland, and for linking them to the public support system for scientific research, technological development and innovation. This also applies to support organizations that have a specific rural focus.

Eight official economic development corporations are operated in the regions, outside the capital region. These corporations service firms, organizations and individuals in different geographical areas. They are usually run as a joint initiative of the state (channelled through the Institute of Regional Development) and the municipalities within each area. However, business associations, trade unions, and other regional organizations in some instances also take part in running the corporations (Nordic Innovation Centre, 2005). In some instances the corporations are directly linked to regional associations of municipalities and act as their offices as well. The corporations' role varies somewhat, but most have a primary focus on facilitating economic development and innovation through specific projects or services to firms, entrepreneurs, organizations and community groups. Usually the corporations have a wide cross-sectoral focus. The economic development corporations usually act as the leader of regional actors in organizing and implementing the before-mentioned regional growth agreements and associated development initiatives.

In addition to the Ministry of Industry and Commerce, many of the other ministries play an important direct or indirect role in the structure that delivers rural and regional development in Iceland. Examples of these are the Ministry of Agriculture, the Ministry of Fisheries, and the Ministry of Communications, which is among other things responsible for the development of transportation and communications infrastructure as well as for tourism development. Furthermore, various governmental organizations operate under the umbrella of these ministries dealing with administration in the respective fields. Most of these institutes are located in the capital region, but in some cases branch offices are also operated in other regions. 
A good example of this is the different status of the communities within the Northeast region, where the town of Akureyri (the largest urban centre outside the capital region) is a growing hub, while the status of many of the communities in the most eastern part of the region is quite negative.

\section{Concluding remarks}

The rural-urban divide in Iceland is greater than in many other western countries. Even if Iceland is a relatively small country of $103,000 \mathrm{sq} \mathrm{km}$ with just over 300,000 inhabitants, there are some signs indicating that that there is limited respect for views of people living under different circumstances. This is clearly evident in relation to the public debate on the harnessing of hydro- or geothermal power for the manufacturing industry.

In rural regions, people want to use energy sources to create jobs and reverse declining population development, while nature protectionists - more active among the urban population, especially in the capital region - want to halt such projects and preserve wilderness areas. Similar debates exist around the building of new road infrastructure in remote rural areas with difficult access to other areas due to long distances around or over mountainous landscape. Many urban dwellers do not think it is justifiable to spend large amounts of taxpayers' money on such projects and instead point out problems of congested roads or roads with high accident rates in or around the capital region that rather need to be solved. Probably the reconciliation of these and other

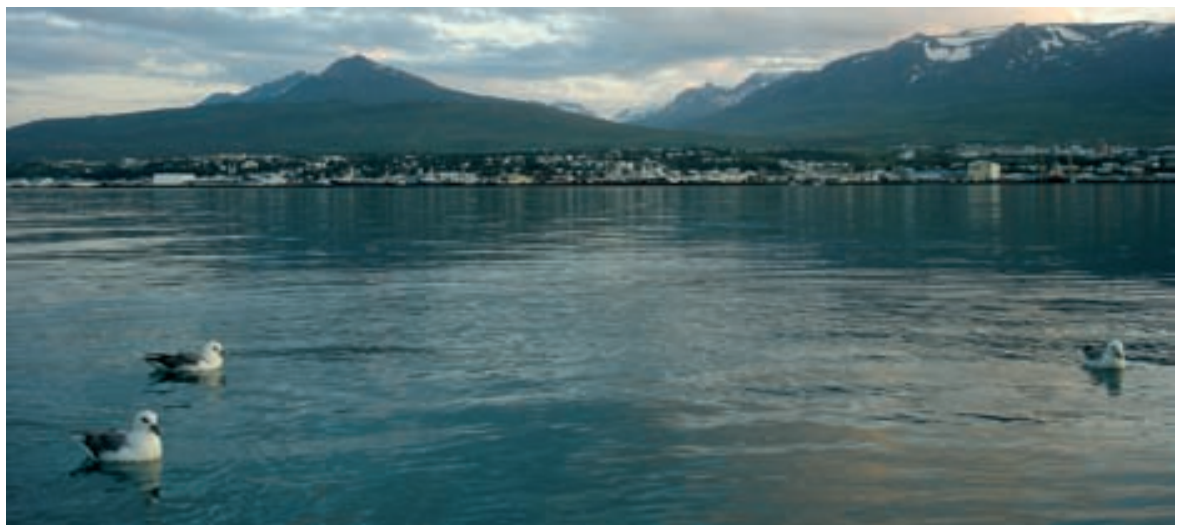

Figure 1: Akureyri is the largest town in Iceland outside the capital region

urban-rural dilemmas will be among the greatest challenges of the next years.

Icelandic rural development initiatives have been changing in recent years from specific support to regions and sectors in distress into a more general policy, including measures aiming at strengthening regions, identified as growth regions. Although a growth centre policy was first touched on in 1991, it took a long time for the government to decide on which regions should be focused on as growth regions.

There are now indications that the growth agreement strategy, which in 2002 was meant to be applied in three regions in Iceland, will be made in most or all of rural Iceland. Thus, there are some signs that the actual results of the growth centre policy might be influenced by the so-called 'watering can principle', referring to the likelihood that the effects will be widely spread and in limited proportions.

The fact that Icelandic rural development policy is in the form of parliamentary resolutions, probably presents one of its weaknesses, as the implementation process is less certain than if it would be in the form of a legally binding Act. In recent years the policy has been characterized by diverse and numerous objectives and measures, often lacking direct measurable indicators or direct linkages to financial planning. This has not only blurred the policy focus, but has also made policy evaluation a challenging task.

Furthermore, challenges associated with geographical definitions of regions make careful monitoring of regional and rural development a problematical exercise. Although the number of carefully prepared studies on rural and regional development have grown, such as the newly released study on economic growth by regions (Institute of Regional Development in Iceland et al, 2007), more effort is needed to carefully define the units of analysis and the associated data gathering techniques used by public entities that have an official role in monitoring development and facilitating positive change.

\section{BIBLIOGRAPHY AND FURTHER READING}

Act on the Institute of Regional Development, no. 106/1999. [In Icelandic: Lög um Byggðastofnun.]

Eðvarðsson, Ingi Rúnar (1998).

Byggðastefna til nýrrar aldar. Reykjavík: Byggðastofnun and Rannsóknastofnun Háskólans á Akureyri.

Institute of Regional Development in Iceland and Institute of Economic Studies (2007). Hagvöxtur landshluta 1998-2004. Sauðárkrókur: Institute of Regional Development in Iceland.

IMD (2006). World Competitiveness Yearbook 2006. Lausanne: IMD.

Impra - Service Centre for Entrepreneurs and SMEs (2006). Information available at the Centre's website at www.impra.is, retrieved Sept. 192006.

Jóhannesson, Hjalti (2007, forthcoming). An Overview of Rural Development in Iceland. In Continuity or Transformation?: Nordic Rural
Development in the Twenty-First Century. Stockholm: Nordregio.

Nordic Innovation Centre (2005). Innovation Systems and the Periphery. Edited by Elín Aradóttir. Oslo: Nordic Innovation Centre.

Parliamentary resolution for a rural development policy 2006-2009. [In Icelandic: Dingályktun um stefnumótandi byggðaáætlun fyrir árin 2006-2009].

Parliamentary resolution on a strategic regional development policy and plan for the period 2002-2005. [In Icelandic: pingályktun um stefnumótandi byggðaáætlun fyrir árin 2006-2009.]

Ríkisstjórn Sjálfstæðisflokks og Alpýðuflokks (1991). Velferðá varanlegum grunni, stefna og starfsáætlun Sjálfstæðisflokks og Alpýðuflokks [pamphlet]. Reykjavík: Ríkisstjórn Sjálfstæðisflokks og Alpýðuflokks.
Statistics Iceland (1997). Landshagir. Reykjavík: Statistics Iceland.

Statistics Iceland (2003). Landshagir. Reykjavík: Statistics Iceland.

Statistics Iceland (2007). Information available at the Institute's website at www.hagstofa.is, retrieved Jan. 2007.

Sæmundsson Rögnvaldur J. and Baldursdóttir Silja Björk (2006). Umfang og umhverfi frumkvöðlastarfsemi á Íslandi 2005. Reykjavík: Rannsóknarmiðstöð HR í nýsköpunar- og frumkvöðlafræðum. Also available online at www.ru.is/ ?PageID $=168$.

The Institute of Regional Development in Iceland [Byggðastofnun] (2006). Information available at the Institute's website at www.byggdastofnun.is, retrieved Sept. 222006.

Valsson, Trausti (2002). Skipulag byggðar á Íslandi frá landnámi til líðandi stundar. Reykjavík: Háskólaútgáfan. 


\section{THE ROLE OF CULTURE IN THE ECONOMIC DEVELOPMENT OF OLD INDUSTRIAL REGIONS}

\section{Guest editors: Paul Benneworth \& Gert-Jan Hospers}

Fuelled by the work of the American guru Richard Florida, cultural assets such as theatres, museums and festivals are increasingly seen as important drivers of regional and urban development. In this line of reasoning, the cultural climate of an area is considered as an important location factor for creative knowledge workers ('the creative class') who are alleged to place high demands on their work and living environment. In particular, old industrial regions looking for new paths of development after severe industrial decline over the years - have been seduced by the promises of this theory.

In this Regional Survey, we discuss to the extent to which culture can contribute to the economic development of Europe's old industrial areas. The papers are the outcome of a successful, third meeting of the RSA working group on Old Industrial Knowledges organized at the University of Twente, 29th-31st January 2007. The first five papers deal with the experiences with culture in old industrial places in the United Kingdom. Clifton and Cooke provide an overview, to show that the creative class in England and Wales - consistent with Florida's theory - is mainly concentrated in diverse, bohemian, socially cohesive and culturally vibrant places.

Four case studies across England follow. Based on her research findings in Birmingham Carole Chapain suggests that a tailor-made approach is needed to stimulate the cultural economy. John Harrison deals with England's North West and the choice for Liverpool as the European Capital of Culture 2008. In her paper on Newcastle-Gateshead Roberta Comunian shows that public support might have both positive and negative effects on local cultural development. Jon Swords - also writing on the North East of England, but focusing on Northumbria's countryside - argues that there is also potential for the cultural heritage cluster in regenerating the economy.

The two final papers in the special issue deal with Finland and Poland. Lavanga shows how the Finnish industrial city of Tampere has developed from a 'Manchester of the North' via an e-city towards a cultural city. Micek reports on the Polish IT industries, where education and embeddedness are more important than cluster development per se.

The common thread linking these papers is that culture can indeed play a role in regenerating the economy of old industrial regions. It is not so much the mere number of cultural jobs that counts, but rather the new image created by culture for regions seeking a new economic future. It is important however to approach culture in a broad sense. There is more than high-brow-culture; popular culture, also contributes to local economic development. From this perspective, Florida's theory has something to offer for old industrial regions as well. Hopefully, this special issue will prompt further debate in a topic that is both fascinating and relevant.

\section{THE 'CREATIVE CLASS' IN THE UK}

\section{Nick Clifton \& Phil Cooke, Centre for Advanced Studies, Cardiff University.}

\section{Introduction}

The replacement of raw materials or other natural endowments with human capital and creativity as the crucial wellspring of economic growth means that in order to be successful in the emerging creative age of the knowledge economy, regions must develop, attract and retain talented and creative people. Such people are not spread equally across nations or places, but tend to concentrate within particular city-regions.

Richard Florida (2002a; 2002b) thus argues that regional economic outcomes are tied to the underlying conditions that facilitate creativity and diversity. Consequently, the 'Creative Class' thesis suggests that the ability to attract creativity and to be open to diverse groups of people of different ethnic, racial and lifestyle groups provides distinct advantages to regions in generating innovations, growing and attracting high-technology industries, and spurring economic growth.
An important research task is therefore to explore the factors that are hypothesised to attract talent, and its effects on regional economic outcomes. In this paper we provide a brief overview of our investigation into the extent to which there are similar processes concerning the relationship between creativity,

Box 1: Mapping the Creative Class in the England and Wales

The Creative Class accounts for some $37.3 \%$ of the workforce; the total figure is split between the Creative Core (9.7\% of the workforce), the Creative Professionals $(25.5 \%)$ and the Bohemians (2.1\%). There is, unsurprisingly, significant variation in concentration across England and Wales; this is highlighted in Table 1.

Table 1: Creative Core Location by Unitary Authority / County

\begin{tabular}{ll|ll}
\hline Top $\mathbf{1 0}$ & LQ & Bottom $\mathbf{1 0}$ & LQ \\
\hline 1. Wokingham & 1.46 & 1. Barnsley & 0.63 \\
2. Reading & 1.42 & 2. Tameside & 0.62 \\
3. Cardiff & 1.39 & 3. N.E. Lincolnshire & 0.61 \\
4. Oxfordshire & 1.34 & 4. Knowsley & 0.6 \\
5. London & 1.33 & 5. Kingston upon Hull & 0.58 \\
6. Newcastle & 1.32 & 6. Sandwell & 0.57 \\
7. Cambridgeshire & 1.31 & 7. Thurrock & 0.56 \\
8. Brighton \& Hove & 1.31 & 8. Blackpool & 0.52 \\
9. Windsor \& Maidenhead & 1.31 & 9. Blaenau Gwent & 0.51 \\
10. Trafford & 1.27 & 10. Stoke on Trent & 0.49 \\
\hline
\end{tabular}


human capital, and prosperity at work in the UK as reported for North America by Florida and colleagues (Florida and Gates, 2001; Gertler et al 2002).

The basic research questions are:

1. Where is the creative class located in the UK

2. What is the potential impact of quality of place upon this dispersion?

Beyond the scope of this brief overview are questions relating to the connection between the location of the creative class and inequalities in technical and economic outcomes within the UK; these are discussed elsewhere (see Cooke and Clifton, 2007).

\section{Results and Analysis}

As might be expected, localities in the west-of-London M4 corridor area (Wokingham, Reading, Oxfordshire, Windsor and Maidenhead) feature heavily in the top ten Creative Core Location Quotients (LQs). In addition to London, ranked at number seven Cambridgeshire completes the third facet of the 'Golden Triangle' of the UK's knowledge economy. What is perhaps more interesting is that in addition to those areas which might be expected to feature, a number of less obvious regional centres of creativity emerge - Cardiff in the West, Manchester in the north west (Trafford lying just to the west of the city centre with Manchester itself ranked only 4 places below at 14), and Newcastle in the north east. Finally, our rankings confirm the position of Brighton and Hove as a creative centre.

Turning attention to the bottom ten UAs, a number of these are places suffering the protracted after-effects of the loss of heavy industry, either as distinct localities (Blaenau Gwent, Stoke on Trent, Barnsley) or the de-industrialised areas of large cities, e.g. Tameside (Manchester),

\section{Box 2 Creative Class and Quality of Place}

As shown in table 2, the indicators for both diversity and the bohemians are positively correlated with the localisation of the Creative Class and both its sub-groups. This means that the Creative Class in England and Wales tends to live in places that also have high levels of bohemians and diversity. Both relationships are quite strong, particularly so for the bohemians. The openness index is a fairly simplistic measure of tolerance and as such might not be sufficient. However, from the above we can tentatively conclude that the Creative Class and tolerance (measured as diversity, and the presence of bohemians) do correlate in the same way that Florida and his associates found in the North American analysis.

\section{Table 2: Quality of Place - Bivariate Correlations}

\begin{tabular}{l|ccc}
\hline & $\begin{array}{c}\text { Correlation } \\
\text { with Creative } \\
\text { Class }\end{array}$ & $\begin{array}{c}\text { Correlation } \\
\text { with Creative } \\
\text { Core }\end{array}$ & $\begin{array}{c}\text { Correlation } \\
\text { with Creative } \\
\text { Professionals }\end{array}$ \\
\hline Openness (Diversity) & $0.52^{\star \star}$ & $0.44 \star \star$ & $0.50 \star \star$ \\
Bohemians & $0.72 \star \star$ & $0.58^{\star \star}$ & $0.71 \star \star$ \\
Cultural Opportunity & $0.52^{\star \star}$ & $0.29 \star \star$ & $0.56 \star \star$ \\
Public Provision & 0.02 & $0.21 \star$ & -0.07 \\
Unemployment & $-0.31^{\star \star}$ & $-0.21^{\star}$ & $-0.33^{\star \star}$ \\
\hline
\end{tabular}

Source: Census of Population 2001; Annual Business Inquiry, Employee Analysis 2002.

* significant at the $95 \%$ level

** significant at the $99 \%$ level

Knowsley (Liverpool) and Sandwell (Birmingham). In addition, places associated with old-style 'bucket and spade' holiday resorts also make an appearance (North East Lincolnshire, Blackpool).

With regard to cultural opportunity, a positive and statistically significant relationship exists between the presence of the Creative Class in a location, and that location's cultural and recreational offer. This finding is again compatible with those of the North American research. This relationship is quite strong for the Creative Class as whole and the Creative Professionals, but somewhat puzzlingly weaker for the Creative Core.

For public provision, a significant and positive (but weak) association is observed for the Creative Core only. For unemployment, the relationship is consistently negative, although moderate and

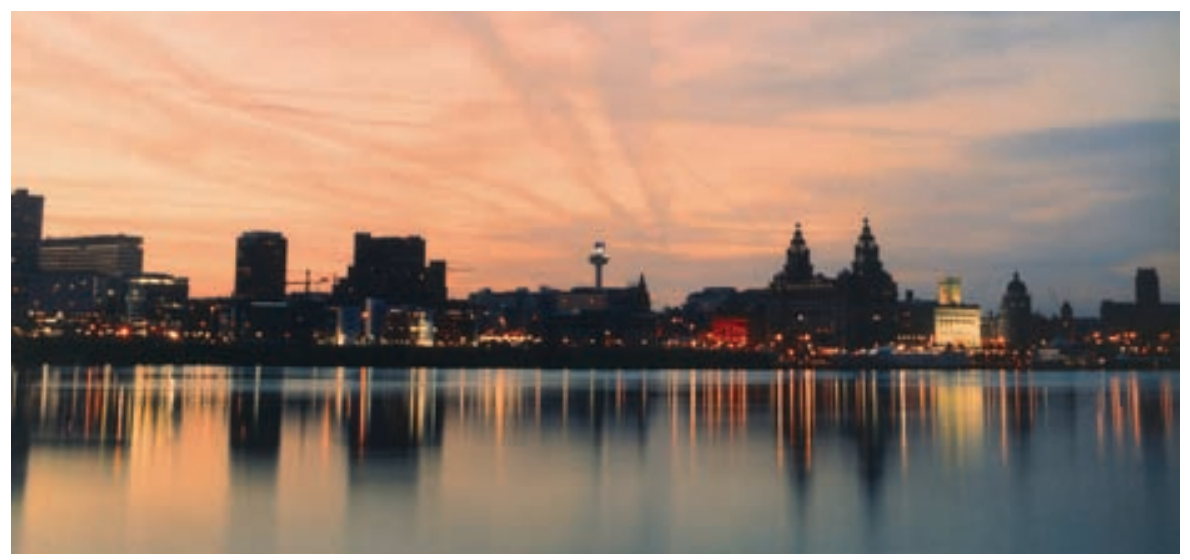

weak with respect to the Creative Core, meaning that municipalities with high levels of unemployment tend to have a low concentration of the creative class.

\section{Conclusion}

The Creative Class in England and Wales appears to show a similar pattern of distribution with respect to quality of place, as is observed in North American cities. High concentrations are found in places which are diverse, bohemian, socially cohesive and which offer higher levels of cultural opportunity. However, while these observations are consistent with Florida's theories, they do not themselves imply any causal relationships; to this end further research involving tools such as multivariate models and qualitative case studies is ongoing.

This research is taking place within the context of a wider project entitled 'Technology, Talent and Tolerance in European Cities: a comparative analysis', involving matched datasets and research partners in Denmark, Sweden, Norway, Finland, the Netherlands and Germany. The UK element of the work is funded by the Economic and Social Research Council, Grant Number RES-000-23-0467. 


\section{CREATIVE BIRMINGHAM (UK)? INSIGHTS INTO CREATIVE INDUSTRIES IN AN OLD INDUSTRIAL CITY.}

\section{Caroline Chapain, Centre for Urban and Regional Studies, University of Birmingham}

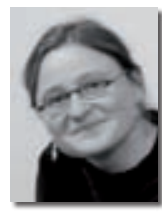

\section{Introduction}

Although the debate on the current importance of creative or cultural industries for the economic development of cities is on-going, few studies actually look at how these industries work in specific cities and how they relate to their location. In part, this has been due to the lack of data. Authors that have studied creative industries in a local context have usually focused on a single sub-sector. For example, Scott (2000) compares the Craft and Jewellery industries in Los Angeles and Bangkok or the film industry in Paris and Los Angeles, whereas Turok (2003) looks at the film and television industry in cities and region of Scotland. Usefully, Pratt (2004) reviewing the current analytical use of the creative cluster concept calls for distinction to be made between 'activities take place and addvalue within that location, and those which take place and leak value elsewhere'.

Pratt's contribution seems particularly relevant in 'transitional' cities such as Birmingham that are undergoing major urban and economic reorganisation as they switch from declining traditional activities. In such places, policy makers have stressed the role of creative industries in the regeneration of some areas or in the creation of a new image for the city. But as Pratt (1997) emphasises, having creative industries is not at all the same thing as being creative. There is a need for policymakers to understand the composition of their creative industries, the constituent sub-sectors, their relationship with the local economy, and how they support cultural/creative life or communities, drive the overall transition to a creative city.

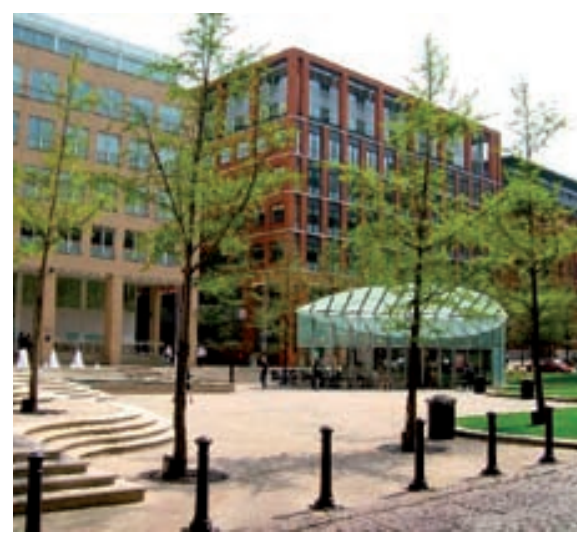

Figure 1: Regeneration at Brierley Hill

Box 1: Background to this study

Influenced by the DCMS 'Creative Industries Mapping Document' (DCMS 1998, 2001) and the 'Creative Industries: The Regional Dimension' (DCMS, 2000), Birmingham like many other UK cities has placed emphasis on developing the sector in recent years. This culminated in 2006/2007 with the recognition of the Creative industries in the policy literature as key areas of growth and future prosperity for the city.

In 2002-2005, the City asked the Centre for Urban and Regional Studies to conduct a study in order to provide policy makers and practitioners in Birmingham and beyond with a better understanding of the growth dynamics of the creative industries in the city. This paper summarises key research findings, highlighting how creative sub-sectors in Birmingham may contribute differentially to local economic and cultural developments. This paper draws on research commissioned by the 'Innovation Team, Creative Development, Planning and Regeneration', at Birmingham City Council, part of the ERDF Creative Knowledge Creative Companies (CKCC) programme. The views expressed here are those of the authors alone.

This article is based on a survey of 349 creative industry firms as well as 31 interviews in Birmingham in 2004/2005. The research used the DCMS (1998) definition of Creative industries and cover sectors like Design/Visual Arts, Screen-based Media and Radio, Performance Arts and Music, Crafts and Jewellery, Software Industry, Publishing and Advertising. Main topics of the survey and the interviews were Business Profile, Firm Performance, Firm History, Products and Processes, Customers, Knowledge Inputs, Skills and Training, Support and Co-operation and Business Support.

\section{Different contributions from creative sub-sectors}

Overall, creative industries are a dynamic and growing part of the Birmingham economy. Most firms are primarily involved in creating and designing, excepting 'Crafts and Jewellery' firms, where manufacturing is the primary activity. Creative firms employ highly skilled and entrepreneurial people. They are in part technologically driven and are contributing to a range of other city-wide business activities including transportation, leisure, construction, manufacturing, and retailing.

They are also closely linked to education and other elements of the public sector. Most creative entrepreneurs are born and bred in Birmingham. They are proud of their city. They frequently develop specific business niches using mostly local resources, and are expressive of local culture and creativity. That is not so say they all contribute similarly to regional development: there are clear differences between the sub-sectors within Birmingham.

The Visual Arts and Design sub-sector is long-standing in the city. The sub-sector is highly skilled, linked to local schools, profitable, growing and very creative. Architecture firms are actually and figuratively building the image of the city. Their work is therefore crucial in urban develop- ment terms. Design firms create branding for local firms and consequently contribute to enhancing the image of the city.

Screen Media and Radio is characterised by larger, nationally based employers, who tend to foster local production. It also contributes to the image of the city as well as to its urban development - buildings are an important feature of larger companies and consequently there is an impact on city architecture. These firms have close links with education organisations as well. The sub-sector is innovative and technologically intense.

The Performance Arts and Music is one of the few that has a strong link with the general public in terms of market orientation. The sub-sector is dominated by micro-firms but also contains some flagship companies that are playing an important role in marketing the city. Some of these firms see themselves as fulfilling an 'ambassadorial' role for the city. These companies are a key part of the city centre 'scene' and they impact on other businesses. They also bring people to the city. Many companies in this sub-sector are involved with local communities. They have strong links with the education and health sectors. However, they rely heavily on the public sector for financial support. 
The Crafts and Jewellery sub-sector is closely connected to the industrial past of the city and is recognised as a city cluster both locally and outside Birmingham. The sub-sector animates one particular neighbourhood. It is active and dynamic and seems to be relatively self-sufficient. However, intensive competition from Asia may threaten its long-term viability.

Publishing/Printing is one of the most important creative sub-sectors in Birmingham in terms of employment. Given its media functions, the subsector is a source of information about what is happening in the city and the wider region. Some firms are engaged in cultural production (books). Some firms have good links with ethnic minorities.

Software is the most important creative sub-sector in Birmingham in terms of employment. This sub-sector is growing and very active. The sub-sector faces many challenges in terms of international competition and regulation, as well as product development and the availability of a local and regional workforce. Given its importance in the global economy, its future development is crucial.

The Advertising sub-sector has been present in the city for some time. Given the nature of its business activities, the sub-sector helps to market local and regional firms. The sub-sector exports and is very profitable. The main challenge is national competition.

\section{Conclusion}

The creative sector in Birmingham cannot be regarded in any way as a homogenous economic entity, contributing in a range of ways to the economic development of the city. This suggest that there is a need for the design and application of a varied set of policy instruments and tools that are tailored to the particular needs and requirements of different sub-sectors. This would enable their specific contribution to the general development of the city to be better exploited.

\section{CULTURE-LED REGENERATION IN ENGLAND'S NORTHWEST}

\section{John Harrison, Globalisation a Manchester's role as a new cultural centre}

Once a bastion of municipal socialism, Manchester's entrepreneurial turn was a tactic to deal with Thatcherite Conservatism during the 1980s. Breaking from the socialist path trodden by cities such as Liverpool and Sheffield, Manchester under Graham Stronger reinvented itself, adopting a less militant, more conciliatory approach to Whitehall, and generally being warmly rewarded. Whilst other northern cities faced a budgetary axe, investment flowed into Manchester into the G-Mex exhibition and convention centre, the Bridgewater Concert Hall and (one of only three nationally) City Pride Status.

This political reorientation paved the way for Manchester to become a focal point for high-end cultural consumption at the beginning of the 21st Century. Manchester has witnessed further investment: The Lowry Centre (2000) in Salford Quays, the Imperial War Museum North (2002) in Trafford Park, and the URBIS Exhibition Centre (2002) in recent years. The announcement last year that the $\mathrm{BBC}$ were to relocate a number of their departments to Manchester reaffirmed the city's claim to be the prime cultural centre outside London.

\section{Liverpool: European Capital of Culture 2008}

Since the European Capital of Culture (ECOC) was first conceived in 1983, and particularly following Glasgow's 1990 success in linking the award to city development, ECOC status has become highly prized as the 'golden ticket' for urban regeneration, particularly amongst Europe's 'old industrial regions': this was certainly the case with Liverpool's bid.

Five UK cities were shortlisted alongside Liverpool - Birmingham, Bristol, Cardiff, Newcastle-Gateshead vand Oxford. An outside bet at the start of the campaign, Liverpool caught up with early leaders Birmingham and NewcastleGateshead, the announcement on 4th June 2003 that Liverpool had secured the title was a momentous occasion for all connected with the city. But on the day prior to the announcement, the media coverage clearly placed Liverpool as an also-ran:

'The clear favourites for the prize are Birmingham and Newcastle-Gateshead... every other bidder had laughed off the city [Liverpool] as too insular.'

So how did Liverpool's campaign gain enough momentum to sneak up and take the prize? When commenting on their decision the panel of independent judges highlighted the following as having swung the decision in favour of Liverpool:

'If one had to say one thing that swung it for Liverpool, it would have to be there was a greater sense that the whole city is involved in the bid and behind the bid.'

Sir Jeremy Isaacs, Head of the Independent Panel of Judges

Although the obvious focus of Liverpool's bid was ostensibly the city of

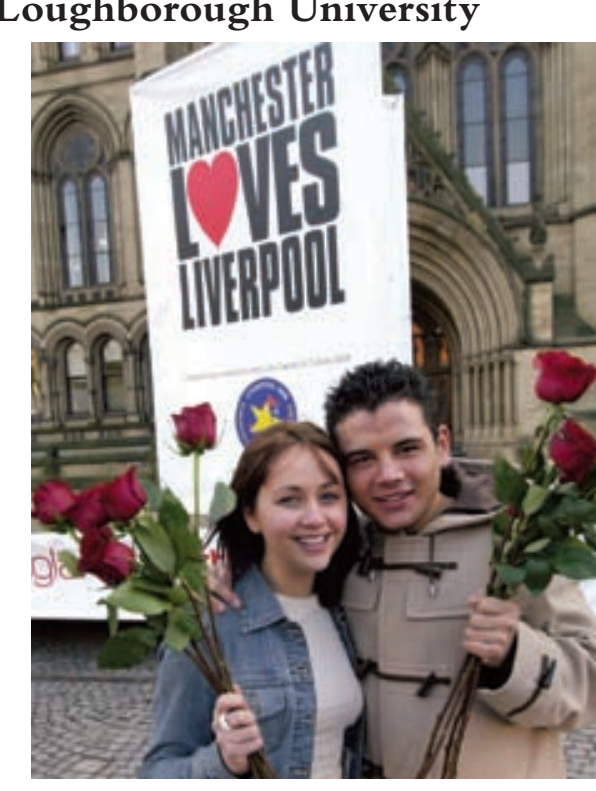

Liverpool, there was a strong push from the wider North West region to actively support Liverpool's bid. This was not unique to Liverpool and the North West, but a series of high-profile events established the broader regional element in Liverpool's bid. In particular, they used the LiverpoolManchester rivalry to positive effect.

The two cities and the Northwest Regional Development Agency (NWDA) commissioned the 'Liverpool-Manchester Vision' Study. A unique collaboration that had never before been attempted, this study highlighted both the links between the two cities and their regional contributions, but also how the two cities interacted to create positive regional benefits.

The two cities developed a concordat which allowed Liverpool to 'borrow' Manchester's experience in winning large event, notably the 17 th Commonwealth 
Box 1: England's Northwest: from industrial to post-industrial region? England's Northwest has long been an important lens through which to observe change in capitalist society. Achieving little until the eighteenth century, the region was catapulted to the forefront of world attention in the late 18th Century with the advent of industrialisation. A regional cluster avant la letter, the 19th Century Northwest was the Silicon Valley of its day. This economic growth and expansion was powered by the two great industrial cities of Manchester (manufacturing centre of the British Empire), and Liverpool (trade and distribution gateway to the colonies).

Barely thirty miles apart, the distinctive nature of each city's industrial economy enabled both to grow at a remarkable rate. With time, however, the inevitable tensions of being so close began to emerge, reaching a peak in 1882 when a group of Manchester businessmen, dissatisfied with the high railway rates and excessive dock dues charged on goods passing through the Port of Liverpool, began the process of constructing the Manchester Ship Canal. This transformed the inland city of Manchester into a major seaport, removing the city's reliance upon their neighbouring city.

A century later, the North West was once again to be found at the sharp-end of rapid economic change. This time rapid job losses in manufacturing contributed to economic stagnation, high unemployment and social affliction within a weakly institutionalised North West region. A generation later and today there is a sense that the fortunes of the region appear to have their foot firmly back on the accelerator. Grossing $\mathcal{E}_{106}$ bn per annum, the North West economy is the largest regional economy beyond London and the South East in England.

What may appear remarkable is that an 'old industrial region' the North West may be, but it can also lay claim to being a region attuned to the benefits of cultureled regeneration. Employing 12\% of the region's workforce and contributing an estimated $f_{15-20 b n}$ to the regional economy, the cultural sector is of meaningful proportions to effect the region's economic recovery. And yet it is a region that has seen little by way of academic research into the role that culture-led regeneration has played in its economic upturn.

Indeed, what remains contentious not only in the North West but across other cities and regions is the balance between culture-led regeneration as a driver of regional economic growth, or whether in fact it is simply a measure of success in other areas? What is known in the North West context is that the two cities of Manchester and Liverpool have had very different experiences of a growing cultural economy.

Games. If bidding for ECOC was a new adventure for Liverpool, its close neighbour Manchester had gained valuable insight into the politics that lay behind the bidding process for similar international showpiece events. Manchester's failed bids to host the 1996 and 2000 Olympic Games had been a springboard for the successful Commonwealth Games bid, the culmination of two decades work by the city's political leaders and their public-private partners. Bob Scott had had the vision to bring the Olympic Games to Manchester, and who then delivered the Commonwealth Games; shortly afterwards the whole team decamped to direct Liverpool's ECOC bid.

Two further events in the run-up to the ECOC announcement provided further high-profile media attention for Liverpool. The NWDA coaxed Manchester to 'declare its love' for its traditional rival Liverpool, by sending a $12 \mathrm{ft}$ x $8 \mathrm{ft}$ Valentine's Day card bearing the inscription:

'Capital culture, And maximum bliss; You're a city that's jumping, So give us a kiss.'

A matter of weeks later, Manchester's support for the Liverpool's bid was further set out with a second high-profile event. The NWDA designed and funded the world's biggest building wrap at $\mathrm{St}$ George's Hall, Liverpool, along with an 82 x 42ft (24m x 13m) banner - unveiled on the Granada Television building in Manchester with the slogan 'Manchester supports Liverpool's Capital of Culture bid' underlining their support for Liverpool's bid, a serious message which helped push Liverpool's bid over the line to victory.

As Liverpool 2008 beckons it is important to note that England's Northwest is not a region where the importance of cultureled regeneration began with the ECOC. $12 \%$ of the regional workforce are currently employed in 'culture' sector, contributing approximately one fifth of the region's economic output. The region has not been slow in becoming a culturally-attuned postindustrial region. With Liverpool's year of showcasing its cultural life and cultural development now upon us, it should not be forgotten that despite the label of 'old industrial region', England's Northwest is a region that has a strong cultural heritage as well as industrial heritage.

\section{THE ROLE OF PUBLIC SUPPORT IN BUILDING A CULTURAL ECONOMY}

\section{The Case of Newcastle-Gateshead and the North-East of England. Roberta Comunian, University of Leeds, United Kingdom}

\section{Introduction}

In every region in Europe, attention is being focused on the cultural economy and the creative industries, 'no region of the country, whatever its industrial base, human capital stock, scale or history is safe from the need for a "creative hub" or “cultural quarter"” (Oakley, 2004, p.68).

In the last decade thriving cities and regions cannot simply be economically successful, they also need to be cool, creative and attractive (Florida, 2002). Cultural events, flagship cultural projects and regeneration are being used by regions throughout Europe to develop a new cultural dimension, an image with unique selling points.

Nevertheless, the cultural dimension often hides a strong economic commitment and the need to consider not only economic results but also the social and cultural impact, which is much harder to measure.
In the UK in the last ten years, since the New Labour government established of the Department of Culture, Media and Sport, the cultural economy and creative industries have been surrounded by policy hype and have become a buzz word. This agenda seems to be further driven by the successful national headlines that the sector has generated: "the Creative Industries accounted for $7.3 \%$ of Gross Value Added (GVA) in 2004. 


\section{DIARY OF FORTHCOMING EVENTS}

\section{RSA Conferences}

Regional Science Association International: British and Irish Section 37th Annual Conference, Marine Court Hotel, Bangor, Northern Ireland. 15th-17th August 2007.

Further information available via RSAIBIS Secretary Don Webber: don.webber@uwe.ac.uk

'Transport, mobility and regional development' Regional Studies Association Winter Conference (previously Annual Conference), London. Friday, 23rd November 2007.

On line booking now available at: http://www.regional-studies-assoc.ac.uk/events/future.asp

\section{RSA Seminars and Working Groups}

‘Employability and labour market policy in European perspective', first meeting of the RSA Working Group, Employment Research Institute, Napier University. 5th October 2007.

Further information is available from Colin Lindsay: C.Lindsay@napier.ac.uk

\section{Academic Conferences}

'Meeting the waves of globalisation - local, regional and environmental response' 2nd Nordic Geographers Meeting, Bergen, Norway. 15th-17th June 2007.

For further information, email grete.rusten@snf.no

'Appropriability, proximity, routines and innovation', Danish Research Unit on Industrial Dynamics (DRUID) Summer Conference 2007, Copenhagen Denmark. 18th-20th June 2007.

Further information and online paper submission available at www.druid.dk/summer2007

Second Global Conference on Economic Geography, Foreign Expert Building Hotel, Beijing, China. 25th-28th June 2007. Information via website: http://courses.nus.edu.sg/course/geoywc/conference/econgeog.html

1st World Conference of the Spatial Econometrics Association, Fitzwilliam College, University of Cambridge. 11th-14th July 2007. Further information is available from http://www.sea2007.com/index.html

‘Europe's Geographical Challenges: Science Meets Policy: international conference on the geography of Europe'. Organised by the European Association of Geographical Societies, Amsterdam. 20th-23rd August 2007. More information is available via the website www.eugeo2007.org

'Regions, localities and landscapes in the new Europe' 7th Moravian Geographical Conference: CONGEO 2007, Amphone Hotel, Brno, Czech Republic. 27th-31st August 2007.

Further information is available at the conference website: www.amphone.cz/index-en.htm

'Local governance and sustainable development' Joint Congress of the European Regional Science Association (47th Congress) and ASRDLF (Association de Science Régionale de Langue Française, 44th Congress), Paris, France. 29th August-2nd September 2007.

More information is available via the website: http://sadapt.inapg.inra.fr/ersa2007/

'The Vital City' 10th Anniversary Conference of the European Urban Research Association (EURA), Department of Urban Studies, University of Glasgow, Scotland. 12th-14th September 2007.

Further information is available at the conference website: www.eura2007.org.uk

'Contemporary dilemmas of spatial development in Europe' Warsaw Regional Forum 2007, Institute of Geography and Spatial Organization, Warsaw. 19th-20th October 2007.

Further information is available on the Institute's website: www.igipz.pan.pl

52nd meeting of the North American Regional Science Association, Savannah, Georgia, USA. 7th-11th November 2007. More information is available via the website: http://www.nasrc.org

'Economic policies in a globalized world', Third Bi-Annual Conference of the German Macroeconomic Policies Research Network, University of Burgundy, Dijon (France). 30th November-1st December 2007. More information available from Louis-Philippe Rochon: Lprochon@Laurentian.ca

\section{Student Conferences}

'Contemporary Greece: Structures, Context and Challenges', The 3rd Hellenic Observatory PhD Symposium, London School of Economics and Political Science. 14th-15th June 2007.

Further information is available at: http://www.Ise.ac.uk/collections/hellenicObservatory

‘The Modelling of (Spatial) Interaction', European Regional Science Association, Bratislava, Slovakia. 2nd-11th July 2007. Bursaries available for eligible students.

More information on the website: http://www.ersa.org/prepare/summerschool2007.html

\section{Practitioner Conferences}

'Reflecting upon the approaches to, and impact of, the evaluation of regeneration initiatives', 7th Annual Conference of the Regeneration Management Research Network, Centre for Urban Policy Studies, University of Manchester. 27th June 2007 For further information contact John Coaffee: Jon.Coaffee@Manchester.ac.uk

\section{Seminars and Working groups}

'Reproducing City Regions', The third seminar of the 'Local Economic Development in an age of peak oil and climate change' series, Salford, Manchester. 19th-20th July 2007.

Further information available at www.liv.ac.uk/geography/seminars/seminarthree.htm 


\title{
ANNOUNCEMENT OF ANNUAL GENERAL MEETING
}

\section{The Regional Studies Association Forty-second Annual General Meeting}

\author{
will be held at \\ The Clore Management Centre \\ Torrington Square \\ London WC1E 7HX \\ on \\ Thursday $22^{\text {nd }}$ November 2007 \\ Beginning at $4 \mathrm{pm}$ \\ Your attendance is requested \\ Pip Tucker \\ Secretary

\section{Agenda}

1. Minutes of the meeting held on Thursday, 23rd November 2006.

2. To receive, and if thought fit, to adopt the report of the Board and the Statement of Accounts 2006.

3. To appoint and fix remuneration for an auditor for 2007.

4. To adopt the following amendment to the Association's Memorandum as agreed in writing by the Charity Commission

4.1.19. Subject to clause 5 below, to employ paid or unpaid agents, staff or advisors and make reasonable and necessary provision for the payment of further remuneration including pensions and superannuation to staff and their dependants.

5. To elect directors (trustees) to the Board and to accept resignations, retirements and co-options if any.

6. To consider and fix the membership rates for 2009 .

7. Any other items for discussion but not decision. 


\title{
Election of the 2007/2008 Association Board
}

The Association's Articles of Association permit a minimum of three and a maximum of 12 trustees who are also the company directors. Each of these people must be either members of the Association in their own name or employees of a corporate member. The Board also has some powers of co-option and has approved some observers.

\section{The present Board is as follows:}

\section{Trustees:}

\section{Executive Officer Posts}

David Bailey, Birmingham University

Pip Tucker, Devon County Council

Arnoud Lagendijk, Radboud University, Nijmegen, the Netherlands

Edgar Morgenroth, Economic and Social Research Institute Ireland

Mark Hart, Kingston University

Andy Pike, Newcastle University

Bernie Fingleton, University of Cambridge

Paul Benneworth, Newcastle University

Andy Cumbers, University of Glasgow

\author{
Chair \\ Vice Chair and Secretary \\ Vice Chair and Chair International Committee \\ Treasurer* \\ Chair, Journals' Management Committee \\ Editor, Regional Studies \\ Editor, Spatial Economic Analysis \\ Editor, Regions \\ Conference Coordinator*
}

\section{Members}

Ron McQuaid, Napier University

Richard Baker, Age Concern England

Member*

Member

Christine Oughton, Birkbeck College

Member, Working Groups

\section{Co-optees}

Mário Vale, Universidade de Lisboa, Lisbon, Portugal

Organiser, Lisbon Conference 2007

\section{Observers}

Ron Martin, University of Cambridge

Robert Hassink, University of Oslo, Norway

Felicity Wray, University of Newcastle

Editor, Book Series

Editor, Debates and Surveys, Regional Studies Student Representative

* Position holder reaches the end of their term at the November 2007 AGM

All members have the opportunity to nominate themselves or colleagues for positions in the Association's management structure using the form given below. If we receive more nominations than there are places for, a ballot will be held at the AGM. Please note that it would be possible to nominate a further term for all the present incumbents.

Nominations should reach the office addressed to The Secretary by Friday, 24th August 2007.

Nomination Form for Election of 2007/2008 Regional Studies Association Board

I would like to propose:

Name:

Address:

Telephone: Email:

who is a member of the Regional Studies Association, for election to the Board.

His/her consent has been obtained YES/NO

Signature of the Proposer: Name of the Proposer:

Institution of the Proposer:

Postal Address of the Proposer:

Email address of the Proposer:

Date:

Please support your application/nomination with a short statement of the skills and experience the nominee would bring to the Board.

To be returned to The Secretary, Regional Studies Association, PO Box 2058, Seaford BN25 4QU, United Kingdom by Friday $24^{\text {th }}$ August 2007 


\title{
NEW TITLE FROM EDWARD ELGAR PUBLISHING
}

\section{The Learning Region}

\author{
Foundations, State of the Art, Future
}
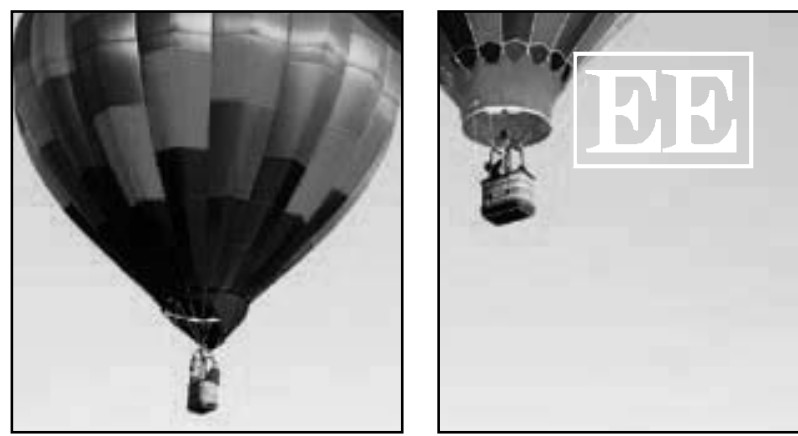

Edited by Roel Rutten, Assistant Professor of Organization Studies, Department of Organization Studies, Tilburg University, The Netherlands and Frans Boekema, Professor of Economic Geography and Extraordinary Professor of Euregional Management, Radboud University Nijmegen and Associate Professor of Regional Economics, Tilburg University, The Netherlands

The aim of this book is to present a much-needed conceptualization of 'the learning region'. The editors scrutinize key concepts and issues surrounding this phenomenon, which are then discussed in the context of recent literature.

This unique conceptualization of the learning region presents a state-of-the-art exploration of theories. Leading scholars from across Europe, the USA and South Africa draw upon various disciplines to explain how regional actors perform regional learning, including: regional networks, industrial districts, the systems innovation approach, social capital and economic geography. Contrary to competing theories, this study takes a relational approach to the learning region. The book thus focuses on learning between regional actors and the ongoing relations they have not only with each other, but also with other actors in their regional social context.

Providing path-breaking theory development in the fields of innovation and regional science and economic geography, this highly original, multidisciplinary study will prove invaluable for students, academics and researchers. Regional policy makers will also find much to interest them within this book.

Contents: Part I: Foundations Part II: State-of-the-Art Part III: Future Index

Contributors include: B. Asheim, N. Bellini, F. Boekema, P. Cooke, R. Florida, R. Hassink, G.-J. Hospers, P. Kenis, M. Landabaso, M. Lorenzen, E. Malecki, M. Meeus, K. Morgan, L. Oerlemans, R. Rutten, M. Storper

April 2007 c 320 pp Hardback $9781843769385 £ 69.95$

To order, please contact:

Marston Book Services Limited PO Box 269, Abingdon OXON OX14 4YN UK Tel: + 441235465500

Fax: + 441235465555

Email: direct.order@marston.co.uk www.marston.co.uk
To request further information, please contact:

The Publicity and Marketing Department Edward Elgar Publishing Limited Glensanda House, Montpellier Parade Cheltenham Glos GL50 1UA UK

Tel: + 441242226934

Fax: + 441242262111

Email: info@e-elgar.co.uk

Sales: sales@e-elgar.co.uk www.e-elgar.com

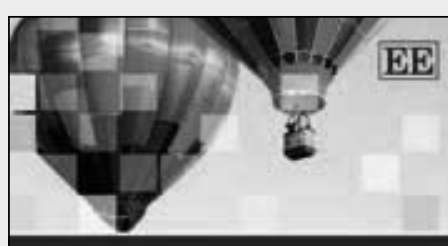

business \& management

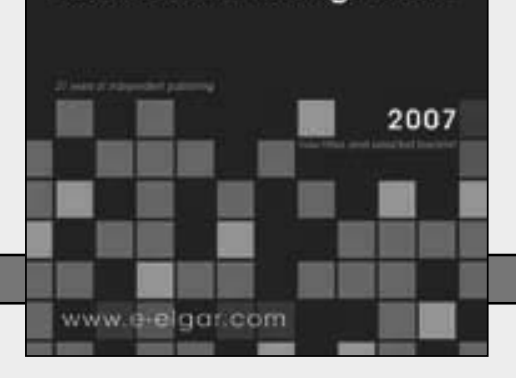


The Creative Industries grew by an average of 5\% per annum between 1997 and 2004. This compares to an average of $3 \%$ for the whole of the economy over this period.' (DCMS, 2005)

However, this successful story is often told without taking in consideration the contributions made to the sector by public funds and without understanding that the cultural and creative economy is not simply another economic sector. In reality it includes many organisation which operates on a not-for-profit or grant-aided level.

The case study of the North-East region of England, and in particular of Newcastle-Gateshead, highlights some of this discrepancy in terms of the role of the public intervention in supporting and shaping the turn from an old-industrial past to a cultural and creative future.

The public support is displayed and articulated at a number of different levels: from investment in the regional public cultural infrastructure; in specific programs and grants schemes, in the support to local networks and infrastructures for the creative economy (see box 1) right through to direct commissions and involvement in the creative economy market.

\section{Building a regional cultural infrastructure}

The first dimension of public intervention in the North-East can be seen in the 1995 document 'Case for Capital'

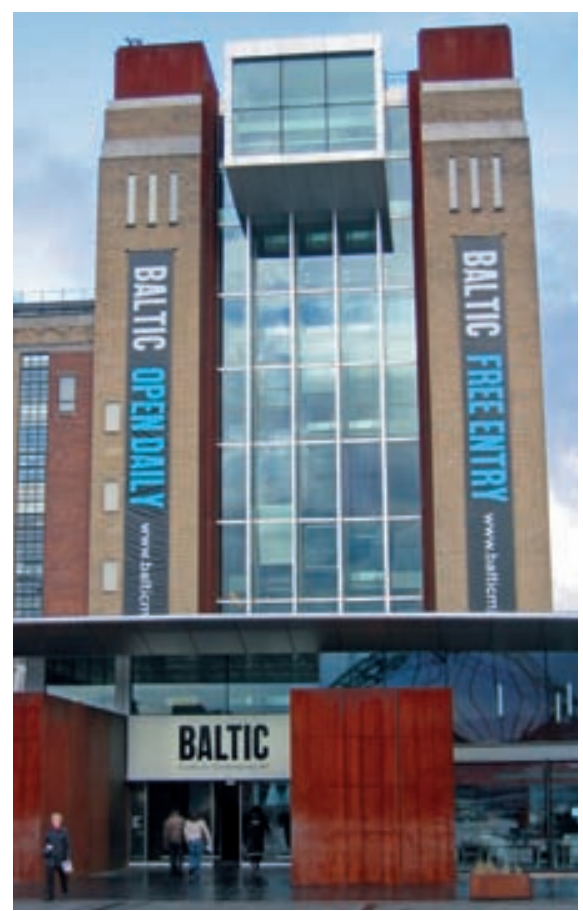

Figure 1: The Baltic gallery is an iconic North Eastern venue

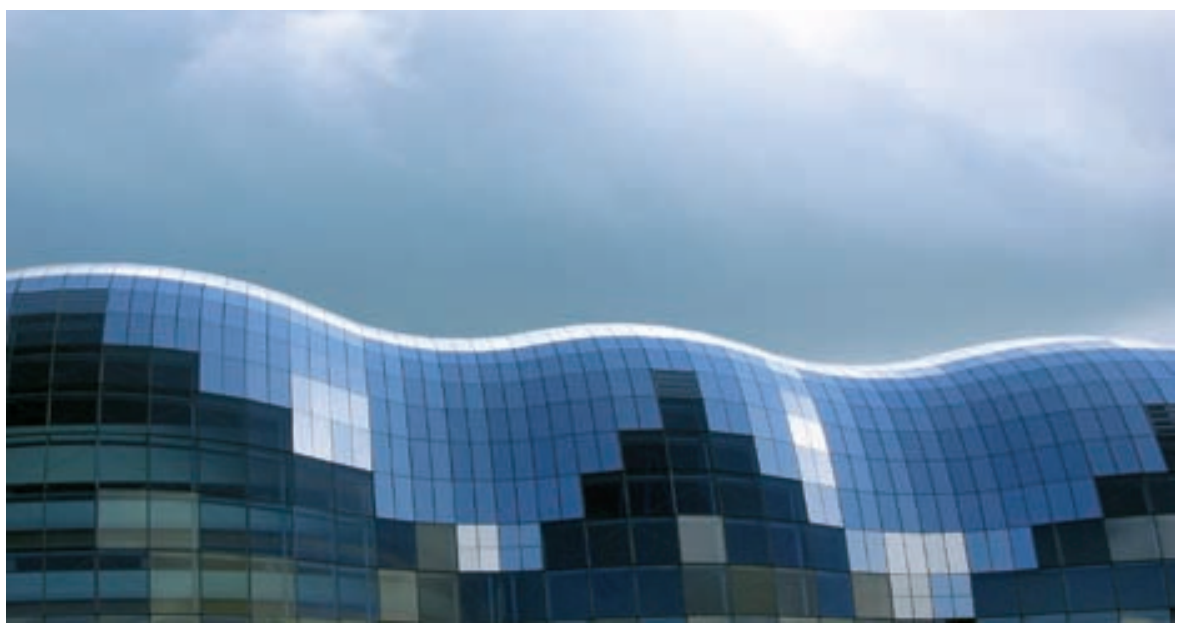

Figure 2: The Sage music centre's roof

submitted by the regional organisation Northern Arts to the central government. This underlined the lack of cultural infrastructure and regional provision, arguing for increased capital investments. In the last decade, central government funding, the National Lottery, European Regional Development funding and other foundations and organisations have invested a total of $f 400 \mathrm{~m}$ in the regional cultural infrastructure.

The results of these investments have become icons of the region and have put the North-East on the international map, creating the condition for the creation of a network of cultural production and programming. The most representative elements of this investment are The Angel of the North, The Baltic and The Sage Gateshead. Nevertheless, the infrastructure includes other less known investments such as the National Glass Centre, Seven

\section{Supporting local creative industries networks}

Local creative industries have created a number of networks for communications, support and exchange. Public policy and funding has supported a range of formal and informal networks as a strategic way to support and sustain the sector. Key examples include:

- 'Cohesion glass artists' network started by the Sunderland city council,

- 'Designed and Made' started organically by a group of artists and makers and then supported by public funding from the Arts Council,

- 'The Artists Network' supported by Northumberland County, and

- 'New Writing North' supported by the Arts Council of England, North East.

The public sector sees these networks as a useful support infrastructure for a number of reasons. Firstly, it allows the public sector to deliver information and support to different people through one organisation. Thus it is an efficient way to spread relevant information, organise meetings and seminars and to involve the larger actors. Secondly, it makes public investments more sustainable: instead of investing in one single person, funds can be used to benefit the whole sector. It is also an effective way to promote the creative industries of the region to other areas, not only presenting the strength and potential of their development; but also helping to promote and marketing them.

Despite the positive aspects of this strategy, public support has the potential to have limiting and negative side effects. On one side it makes the network appear much more institutionalised and bureaucratic. If we consider how much interaction, support and participation come from social networks, turning them into public support organisations to deliver specific outcome can be risky and can change the nature and the quality of the network itself. It is also important to consider the limit of the network: people who do not want to take part in a specific network or who simply do not fall into the remit of the network can feel pushed aside and cut off from the possibility to interact further.

One further aspect is the potential incompatibility between large regional capital investments and the support of local networks. It can be seen that public funds are more easily directed towards big institutions or infrastructure, while networks representing a 'soft' infrastructure can easily be overlooked. 
Stories Centre for Children Books, Dance City, MIMA, and refurbishments project for other well-established organisation such as the Live Theatre, the Northern Stage and the Tyneside Cinema.

\section{Commissioning and investing in the creative industries}

Public sector investment is not limited to the creation and support of the creative and cultural infrastructure. The public sector also plays an important role also in commissioning and marketing the creative industries. Funding for public art commissions is strong in the region, whilst individual buyers and collectors have been encouraged to create a market for contemporary art by the interest free loan offered within the national 'Own Art' scheme.

Furthermore, publicly funded organisations such as Culture10, Newcastle Gateshead's marketing destination agency directly creates programs of events and endeavours to involve local cultural producers and practitioners. Further opportunities for sector and market growth are made available by putting young people and other particular audiences in contact with artists through workshops, talks and projects in schools and in conjunction with the Creative Partnership.

\section{Direct support and grants}

In the North-East, a specific grant scheme 'the Culture Business Venture' has been developed to provide financial support to new creative SMEs. The grant - with a value up to $£ 10,000$, aims to increase the viability and sustainability of creative businesses, encouraging job creation and to support their growth within the region. Since it was established in 1999, it claims to have provided support for over 800 businesses and has helped to start more than 600 new enterprises.

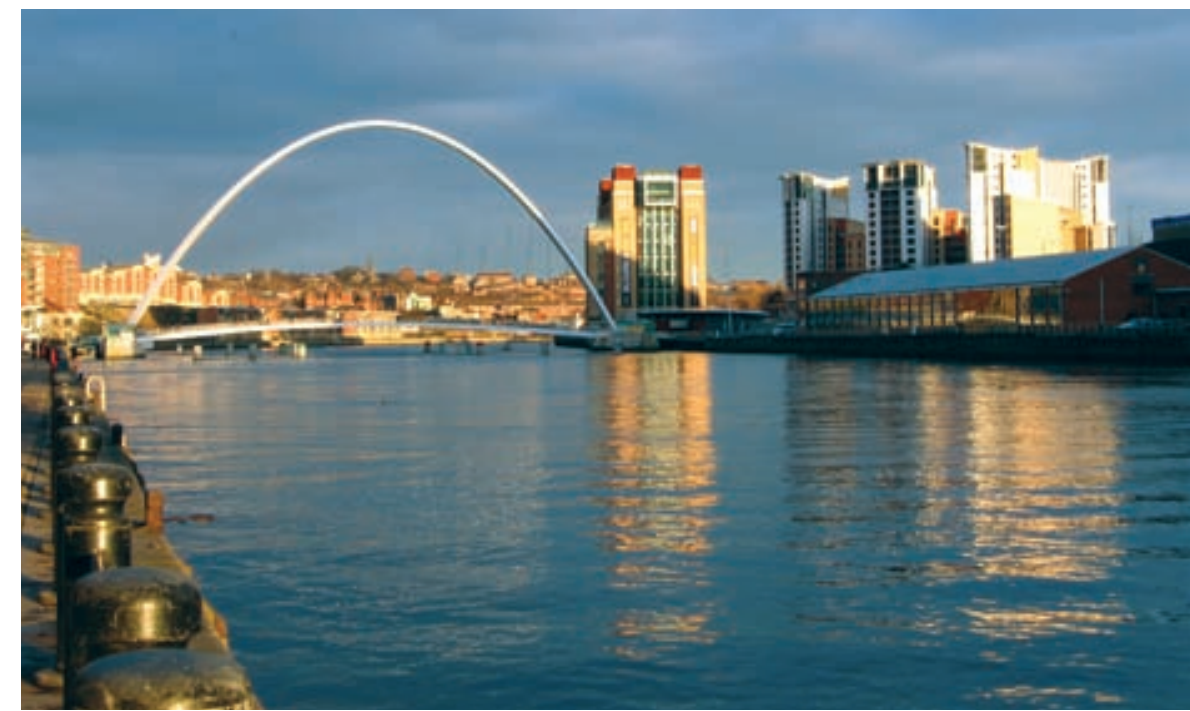

Figure 3: Regeneration has given the Tyne riverscape a face-lift

\section{Public support and sustainability}

The issues presented highlight an often-obscured reality, namely that the transition from old-industrial economies to creative and cultural economies does not happen overnight and require a great amount of intervention, investments and support.

The important role played by the public sector in the development and growth of the local creative economy raises issues of sustainability, particularly given the personal goals of those driving most SMEs in the sector. Northern Film \& Media (2004) underlines the fact that $90 \%$ of the SMEs in the film and media industries in the North East do not see commercial goals as their main focus: 'many owners of firms did not see themselves as entrepreneurs but rather felt they were contributing cultural or social capital to the region' (NFM, 2004, p.20).

What does this mean for an old-industrial region trying to enter the creative and cultural economy? Can the creative industries really become the economic driver for post-industrial regions? Investing in culture and expecting high economic return or attributing economic ambitious to the sector can prove to have a more negative than positive effect. It is important to take in consideration not only the economic dimension of culture but also its contribution to social and cultural development of regions, which cannot simply be defined by numbers and economic outputs.

There is a common misunderstanding undermining the relationship between culture and regions: while policy-makers wonder what culture can do for oldindustrial region economic development, cultural organisation and practitioners are asking what regions and public policy can do for culture in terms of support and investment. It is clear that there needs to be clarity and transparency in these issues, and a consensus between support agents and cultural entrepreneurs before a cultural support policy can make a substantive contribution to building cultural economies in old industrial regions.

\section{HERITAGE LED DEVELOPMENT IN THE NORTHUMBERLAND HERITAGE CLUSTER}

\section{Jon Swords, Centre for Urban and Regional Development Studies, Newcastle University.}

\section{Introduction}

The North East of England is an archetypal old industrial region. The area went through intense development during the 19th and early 20th centuries as coal mining was developed. This fuelled an iron and steel industry, which in turn spawned shipbuilding, heavy engineering and later chemicals manufacture.
However, from the 1930s onwards the North East economy declined as it failed to compete as the UK economy became more open to international competition. Recession and restructuring in the coal and steel industries in the 1980s and 1990s was devastating as tens of thousands lost their jobs.

By the end of the 20th Century the region became based on a classic branch plant economy. However, in 1995 the North East received an economic fillip when Siemens announced a $£ 1.1$ billion investment in a microchip factory in North Tyneside. The plant came on stream in 1997, but was closed 18 months later in 1998 due to conditions in the semi-conductor market. A month after 
Siemens left the region Fujitsu closed its microchip factory in Durham.

In 2001 the North East was hit by the foot and mouth crisis which affected farming, local food producers and tourism. The impact was devastating as 317,000 sheep and 54,000 cattle were killed to stop infection spreading: the financial impact is thought to have cost the region over $\mathcal{E} 170$ million (Phillipson et al, 2002).

\section{Cultural economic \\ development in a rural area}

Within Northumberland a different kind of cultural strategy is being adopted. Development is very much from the grass roots, community focused and fostered by a range of organisations - public and private - alongside environmental objectives. One aspect of this development is done through the county's heritage because, while economically poor, Northumberland has a rich history dating back 10,000 years to the Mesolithic period, via the industrial revolution, the Kings of Northumbria, early Christianity and the Romans. Northumberland is also an incredibly beautiful place; the landscape is amongst the most unspoilt by modern development in the UK.

These historic and natural assets has seen the emergence of an embryonic heritage cluster made up of firms, individuals and public organisation in the cultural, food and drink, heritage, tourism and land-based industries. The Northumberland Heritage Cluster (NHC) is an interesting example of a cluster because while is exhibits the usual characteristics seen elsewhere for example collaboration between colocated firms, socio-cultural institutions, shared learning and social embeddedness -it also exhibits elements not seen in other clusters. Namely, that economic gain is not the central aim of activity of the agglomeration.

Developing and improving the community and environment are also important aspects of what firms, organisations and individuals are trying to achieve. This is partly due to the presence of a number of influential organisations funded by public monies, but also because of the intense connection formed between individuals and Northumberland as a place, fostered through its heritage.

Heritage, in whatever form, while having an obvious connection to the

past is also incredibly embedded geographically. The history of whiskey making in the Cheviots, or the role the Romans played in shaping the landscape of Tynedale cannot be found anywhere else. In this way the heritage of an area is a unique asset and its distinctiveness can be successfully harnessed.

Moreover, whereas control over the Siemens and Fujitsu microchip plants was in Germany or Japan, the power to decide the future of Hadrian's Wall or the Northumberland National Park is held locally by local people. This is essential, not only because local businesses rely on these assets for their livelihoods, but also because heritage is owned by local people, it is their heritage to develop how they see fit.

Of course the heritage or tourism industries will never be able to fully replace the kind of industry which once dominated Northumberland and the North East, but it can go some way to helping improve the economic prospects of areas in need of development, and it can help enrich people's lives through interaction with the past.

\section{Rural cultural industries: in what sense a cluster?}

In terms of a wider research context, the presence of community-centred projects based on heritage mean the NHC is set apart from the traditional kinds of cluster one reads about in the literature. Most cluster research is focused on the usual suspects of bio- and hi-technology, media, automotive or quality manufacturing. As a result, theories and concepts become

\section{Box 1: Culture and regional development in the North East of England}

In recent years culture has become more central to the development of the North East in line with many other places. Flagship developments have been built, expanding the arts and cultural base of the area. Perhaps the most dramatic changes have been on the Newcastle-Gateshead quayside. Once the home of heavy industry it is now dominated by bars, restaurants, and arts venues such as the $\mathcal{L} 70 \mathrm{~m}$ Sage Music Centre, the Baltic Centre for Contemporary Art and the Millennium Bridge.

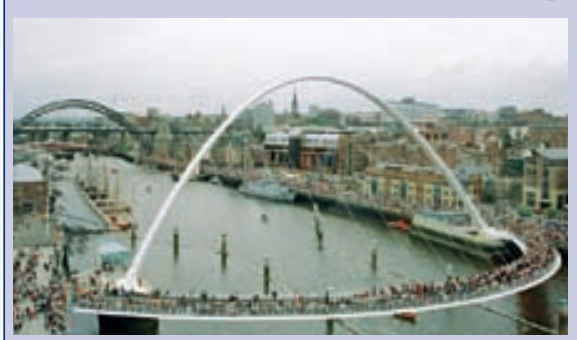

Figure 1: Flagship projects have led cultural development in the North East
A number of scholars have criticised this type of development because "cultural strategies suggest the utter absence of new industrial strategies for growth" and because culture-led developments often only 'articulate the interests and tastes of the post-modern professional and managerial class' (McGuigan, 1996: 99). Moreover, such flagship projects are usually built in urban areas and rarely benefit rural communities. 
like Silicon Valley for example. This newer form of clustering contrasts with the sort of agglomeration which emerged more organically as particular place based assets gave an area an advantage or where local conditions provided the right environment from which a cluster could grow (for example Hollywood, Silicon Valley or Motorsport Valley).

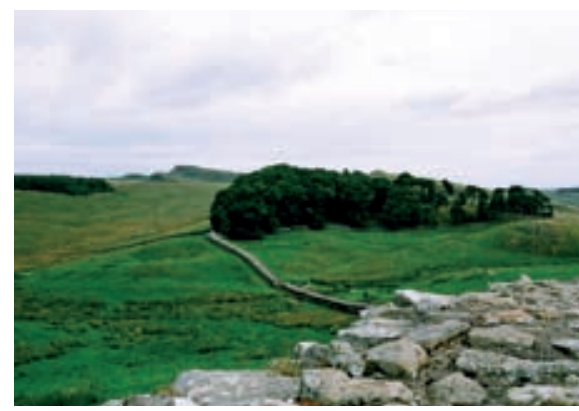

Figure 2: Hadrian's Wall is a UNESCO heritage site
In this case the NHC could not have developed anywhere else because the heritage of Northumberland cannot be found anywhere else. And there has been no top-down policy intervention in the cluster, no strategy to attract firms from outside the area into the cluster; it has been a very uncultivated development with deep roots fostered by people who, together, have a drive to see it grow it because of their attachment to Northumberland as a place. Although the notion of a common goal has been identified as important in a cluster - where an industry has a collective motivation to grow and expand - this case differs - and the importance of heritage comes in - is this attachment driven by the people, history, culture and natural environment of Northumberland as opposed the firm or industry in which someone works.

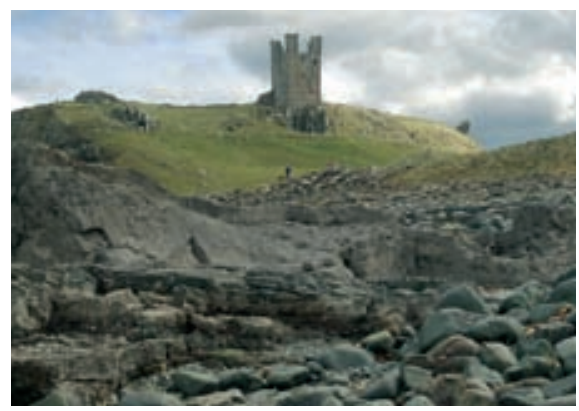

Figure 3: Northumberland is a land of a hundred castles

Similarly however, these factors are the key assets on which the cluster and the activity of organisations in the cluster are built. These are also the elements that make Northumberland a special and unique place. Any further development of the NHC will need to have this at its centre or risk the very thing upon which it is based.

\section{THE ROLE OF CULTURE IN AN OLD INDUSTRIAL CITY. PIONEER TAMPERE!}

\section{Mariangela Lavanga, Amsterdam institute for Metropolitan and International Development Studies (AMIDSt), University of Amsterdam, The Netherlands. Introduction \\ In the last three decades local and national \\ ing more comprehensive, more inclusive and process-oriented. This is not incom- patible with economic development, \\ The new Tampere: E-city \& cultural city} governments have recognised the importance of culture in local development, promoting policies to reinforce the interlinks between them and increase the attendant benefits. Cities are today struggling and competing for reinventing themselves into creative centres. However, there is no pre-determined formula for success. History matters. And what if a city has a strong industrial history? How can culture contribute to the transition to a post-Fordist society? How can culture produce long term benefits and trigger a more sustainable urban development process?

During the 1970s the emphasis of cultural policies was on personal and community development, cultural participation and the revitalisation of the public social life. The experience of the 1980 s was innovative in the symbolic and economic spheres, linking cultural policy with city marketing and strategies aimed at expanding tourism and other consumer service industries.

Now a combination of both the approaches is required. Urban cultural policy-making today is moving into a new direction in order to support the competitiveness of cities in the knowledge-based economy. Urban cultural policy is becomrather it is about improving the quality of life in the public realm, creating more balanced, democratic and civilised cities.

Much of the old industry has managed to retain its significant role despite the industrial recession following the col-

\section{Box 1: The old Tampere: culture and consensus}

At the end of the 19th century, Tampere was one of the largest industrial centres in the Nordic countries, nicknamed 'the Manchester of the North'. The Scotsman James Finlayson could be considered the real industrialist of Tampere, opening a cotton mill in Tampere in 1828, thereby creating what would become the first major industrial establishment in the country. The second half of the 19 th century was an era of great economic, social and cultural development in Finland. Tampere got water pipes, sewers, electricity as well as two theatres, several newspapers and five schools providing university preparation (Hietala and Kaarninen, 2005).

Consensus was based on three factors: a) a well organised and strong labour movement, b) a big industry institutionally owned, and c) a nationally-minded, educated elite. These forces of socialism, capitalism and nationalism succeeded in creating a model of social development which secured economic growth, democracy and stability. Tampere was a pioneer in organising opportunities for study and self-improvement for the working population. In 1912 the technical institute was founded thanks to the Tampere Technical Society; the Tampere City Library, once a private library, was taken over by the City in 1861 and was used to organise basic education, lectures and debates for the working population.

In the beginning of the 1960 s, the relative proportion of industrial jobs begun to decline (Kostiainen and Sotarauta, 2002). In that period the city invested in new higher education and research opportunities, founding two universities. Since then, the universities have been supporting industrial development by educating qualified workforce, co-operating with industry in research, building up the new competence base for the local development. In the 1990s the high-tech industry emerged as a key growth cluster. 


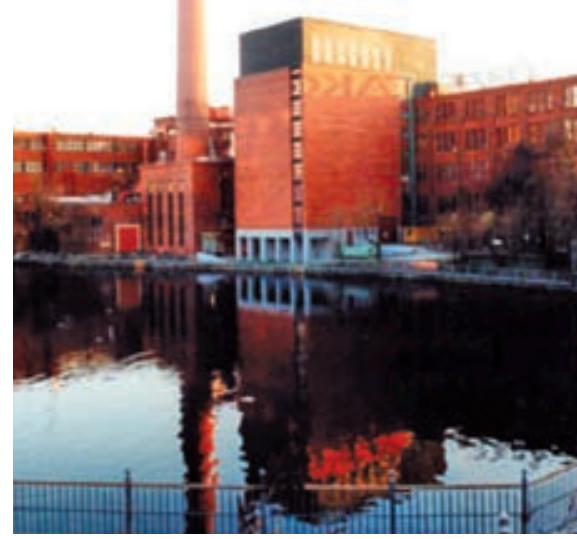

Figure 1: Tampere city centre (Source: picture by Mariangela Lavanga)

lapse of the Soviet Union, succeeding in renewing and developing new high-tech products. Several companies, like Nokia, became globally competitive. By the end of the 1980s the city progressively developed a knowledge-based economy and an information society (Sotarauta and Kostianen, 2005). At the end of 2000, the eTampere Information Society Programme (2001-2005) was launched to accelerate the development of the information society in a more comprehensive way, both economically and socially.

Tampere is neither a capital city like Helsinki nor a traditional heritage city in such as Turku, Finland's former capital. However, its industrial image has not prevented the city from developing itself into an active cultural centre. During the 1960s the city became a vibrant centre for theatre and festivals. The cultural institutions were born almost when the factories closed down, linking and reflecting the city's past history to its present identity.

The residents are the main cultural consumers; a substantial percentage of the municipal budget is allocated in the cultural sector; special attention is given to cultural accessibility, art education and youth centres. Tampere is today known to be a festival city (more than twenty well-established festivals per year), the theatre capital of the country, and an important educational centre in arts and culture, hosting several museums, the biggest city library in Finland, the Tampere Municipal Library $(1.2 \mathrm{~m}$ visitors every year) and the largest con- cert and congress centre in Scandinavia, the Tampere Hall.

Structural industrial change in the 1980s meant a gradual transformation of the use of the industrial site in the city centre and the start of the planning of the area's redevelopment at the end of the decade. Today, Finlayson is becoming a versatile centre for communication technology and multimedia, housing more than 80 companies (among which a sizeable concentration of designers, media, advertisement producers) with over 3,000 employees, a theatre complex, restaurants and cafés. The intensity of activities repeats the historical intensity of the industrial past.

\section{Creative Tampere?!}

The industrial history of Tampere never ended but still continues today. The social organisation seems to rely on the old structure: growing industrial production, wide public sector and political consensus. Tampere is able to develop new products, maintaining productivity, social mobility and cohesion. The longterm investment in education and culture has built a solid base and foundation for creative innovation.

As a natural evolution of the eTampere programme, in April 2006 the city approved the new business development policy programme 'Creative Tampere', to be implemented in 2006-2011. The programme aims at translating the solid cultural expertise of Tampere into commercially profitable ventures. The programme is divided into three intertwined segments: cultural industry, service innovation, creative structures. The City acts as a facilitator while the implementers are businesses, research and educational institutions, associations and other organisations.

The Creative Tampere programme was prepared in close co-operation with

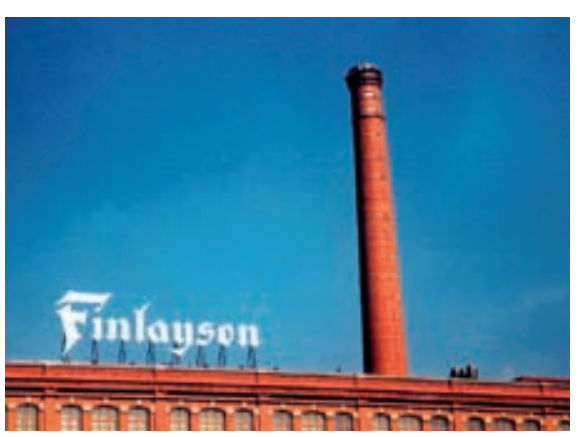

Figure 2: A view of the Finlayson building (Source: picture by Mariangela Lavanga) the bid for the selection of the Finnish European Capital of Culture in 2011. The two programmes could be understood as complementary: Creative Tampere fostering the more commercial side and economic potential of culture and the 'Flow of Culture - Tampere 2011' promoting the more cultural side and revitalisation of the historical industrial identity of the city.

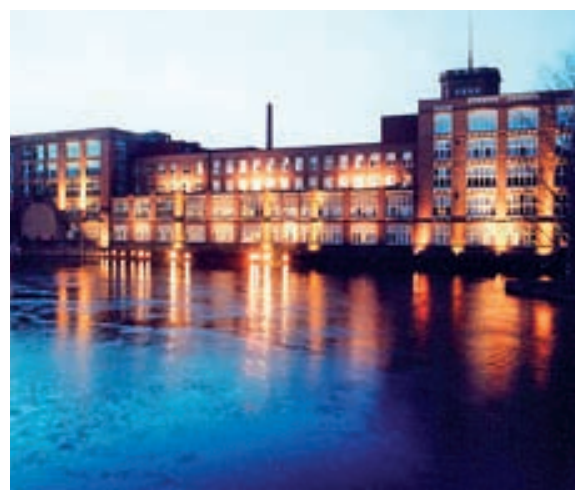

Figure 3: A view of the Tampella building (Source: picture by Mariangela Lavanga)

\section{Conclusions}

Culture has the potential to contribute to a more complex process of urban development and redevelopment: it provides communities with a higher - although not precisely measurable - quality of life in terms of immaterial benefits and it is also able to generate material benefits for the economy and the society as a whole, directly and indirectly. It is necessary that a city find a balance in the nature of investments so that all the pillars are maintained and enhanced: cultural capital, social capital and economic capital within a reasonable spatial organisation.

Several important elements in the success of Tampere have been visionary people, belief in education and culture, risk-oriented attitude, trust and cooperation. Tampere was able to re-invent itself into an e-city, a cultural city and a creative one. The sustainable attitude of Tampere reflects the way the city was and remains able to strategically adapt itself to each phase of the social, cultural and economic development as a pioneer, recognising various changes and adjusting to them, while creating its urban development trajectory.

Culture in Tampere can be equated with democracy, equality and freedom. The cultural infrastructure and activities are strong and built upon a solid foundation. The city strongly believes in culture, education, technology and 
cooperation. The role of the technical schools in the past and later of the new universities has been fundamental for the (re)development of the city. Their embeddedness and commitment are very strong. The cultural investments allowed the (re)definition and reinforcement of the city identity and its participative and inclusive character.
At the same time, cultural investments produced benefits in terms of improvements in city image.

Both processes reinforce themselves in a virtuous cycle. The case study of Tampere shows to what extent investments related to the improvement of the city image - although they can produce short term benefit - need to be integrated with investments aimed to strengthen local identity to be able to produce long term benefits and trigger a more sustainable urban development process. Tampere may well astonish us again. Let's see what the city will reinvent after the government decision to appoint instead Turku as European Cultural Capital in 2011!

\section{THE EMERGENCE OF IT CLUSTERS IN EASTERN EUROPE: THE CASE OF POLAND}

\section{Grzegorz Micek, Jagellonian University, Krakow, Poland}

In the first years after the fall of socialism, growth in Poland's IT industry was concentrated in Warsaw, but more recently, there has been some spatial deconcentration towards smaller cities such as Sopot, Rzeszow. Currently, there are three main regions where there are IT agglomerations: Warsaw, Upper Silesia and Trojmiasto metropolitan areas. Krakow and Wrocław have also been identified as home to concentrations of the IT sector. There is still a substantial lack of IT companies in broader metropolitan areas of large cities outside this main core. This backs up the commonly accepted perspective that companies in new industries in less developed countries cluster almost exclusively in large cities: the deconcentration takes place down the cities' hierarchy but has yet to become a substantial phenomenon below the top tier of cities.

The most important factor behind spatial localization is the relation of founders with the location of the company. Over two-thirds of companies interviewed were established in a place where managers had been living, studying or - admittedly less often - working. A significant determinant for foreign greenfield investments was the Polish origin of foreign managers.

Public sector support plays a very limited role in foreign direct investment in the IT sector. Surprisingly, in the case of Polish companies accessibility of highly qualified labour is not perceived by managers to be a significant factor - rather, it tends to be taken for granted. However, this perception is starting to change as the labour market for IT skills has tightened, with many foreign investors willing to pay higher wages than indigenous companies.

There are two factors which suggest that these disparate investments are beginning to cohere into agglomerations. The first is that some IT agglomerations are beginning to establish themselves through spin-off processes, notably Gliwice, Krakow and Wrocław. It is important to make the distinction between the importance of different types of 'parent' companies to spin-offs: the greatest significance comes from universities and public research laboratories, whilst firms do not make a significant contribution. Indeed, spin-offs from foreign owned IT companies are very rare. This is a problem in the sense that not many of these spin-off companies are formed to sell particular solutions (market facing) - and most are formed to develop particular technologies.

The second type of geographical concentrations may be explained by agglomeration effects. Growth of these concentrations is enhanced by a big demand from existing companies and institutions. The IT agglomerations in the capital city, Warsaw and Katowice and Bielsko-Biala can be categorised in this way.

\section{Policy implications}

Among policy makers it is currently fashionable to develop clusters, and indeed, in the case of Poland, many counties have adopted some version of a cluster development policy. The problem is that these approaches do not fit the needs of the actual agglomerations that exist. The research suggests that there are other approaches necessary to ensure that the IT industry in Poland continues its growth trend.

Unfortunately, Poland has seen an erosion of its surplus of a relative abundance of educated staff; from a position of strength several years ago, it is currently a relative weakness. Indigenous companies face a particular pressure from losing their most skilled software developers. The development strategies based on an assumption of a continuing 'abundance of highly skilled graduates' into the future is unlikely to succeed. The greatest policy efforts in maintaining the growth of the IT industry in many Polish cities should be focused on attracting graduates and young PhDs and starting short and flexible, reskilling education programs for potential software developers.

Regional policies should be also focused upon towards enhancement of regional embeddedness of foreign companies, which demonstrate a substantial lack of local sub-contractors. The research also would support a direct targeting of ex-pat Poles working in the UK, US and Ireland; they have a high

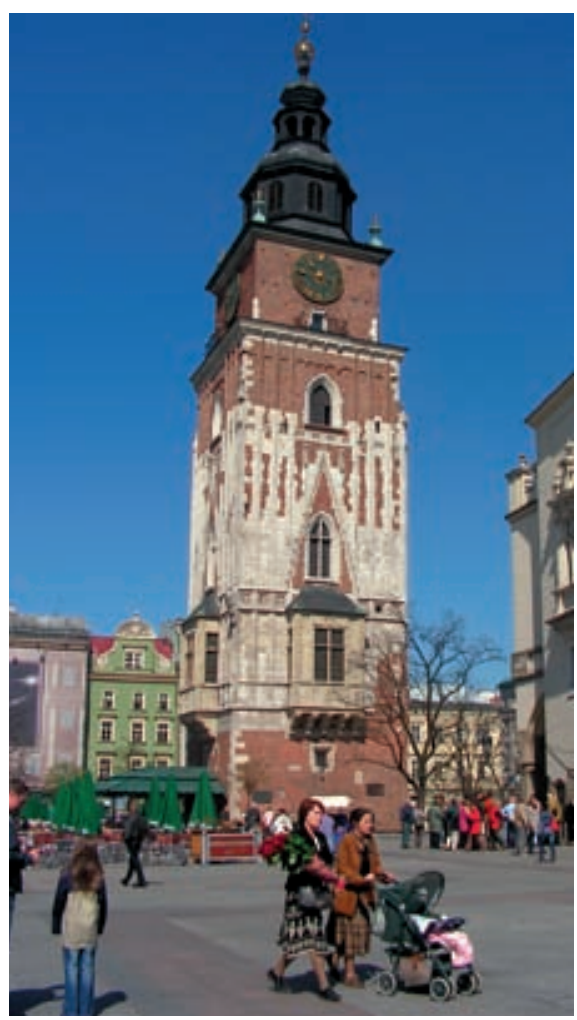

Figure 1: The main market square of Krakow 


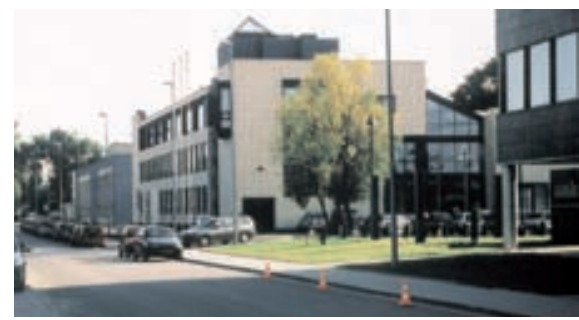

Figure 2: ComArch - Krakow's largest indigenous company.

number of Polish software developers not only working there, but sometimes holding managerial positions and can be in decision-making positions for the establishment of new filials.

Policies developed by metropolitan regions should be directed towards supporting office sites outside city boundaries in attractive areas located nearby residential neighbourhoods. A final suggestion is that for cities and regions outside the current core regions, there is an opportunity to exploit the linkages that their IT companies have with successful firms located in core regions, which have stronger growth potentials based on spin-off effects and agglomeration economies. This may create the twinning effect when experience from academic research will be joined with market opportunities and vice versa.

This article reports results from a research project financed by Ministry of Education and Science (4471/P04/ 2005/28), based on over 130 in-depth interviews with founders and managers of IT companies in Krakow, Upper Silesia, Bielsko-Biala and Mielec.

\section{Bibliography and further reading}

BBC News (2003). 'Liverpool named Capital of Culture'. BBC News Online, 4 June.

Burfitt, J.A., C.A. Chapain, C.J. Collinge, J. Gibney, R.J. Lutz, A.R.G. Barber. 2005. The Development of the Creative Industries in Birmingham, A Project under the ERDF Funded Creative Companies, Creative Knowledge Programme (CKCC), Birmingham City Council, Birmingham, School of Public Policy, The University of Birmingham.

Amin, A. and Thrift, N. (1994). Living In The Global. Globalization, Institutions, and Regional Development In Europe. A. Amin and N. Thrift. Oxford, Oxford University Press: 1-22.

Amin, A. and Thrift, N. (1995). Globalisation, Institutional 'Thickness' and The Local Economy. Managing Cities: The New Urban Context. P. Healey, S. Cameron, S. Davoudi, G. Graham and A. Madanipour. Chichester, John Wiley: 91-108.

Bailey, C., Miles, S. and Stark, P. (2004). 'Culture Led Urban Regeneration and The Revitalisation Of Identities In Newcastle, Gateshead and The North East Of England'. International Journal of Cultural Policy 10(1): 47-65.

Bianchini, F. (1993). Remaking European cities: the role of cultural policies. In: F. Bianchini and M. Parkinson (Eds.) Cultural Policy and Urban Regeneration: the West European Experience. Manchester: Manchester University Press.

Clifton, N. and Cooke, P. (2007): The 'Creative Class' in the UK: an initial analysis, Regional Industrial Research Report 46, Centre for Advanced Studies, Cardiff University.

Crompton, J. Beyond Economic Impact: An Alternative Rationale for the Public Subsidy of Major League Sports Facilities. Journal of Sport Management. Vol.18 (2004), p.43.

Dawley, S. (2007). 'Placing Fluctuating Rounds Of Inward Investment In Peripheral Regions: Semiconductors In The North East Of England'. Economic Geography 83(1): 51-74.

DCMS (2005), 'Creative Industries Economic Estimates Statistical Bulletin'. London: Department of Culture, Media and Sport.

Department for Culture Media and Sport (DCMS) (1998). Creative Industries Mapping Document. London: DCMS

Department for Culture Media and Sport (DCMS) (2000). Creative Industries: The Regional Dimension report of the Regional Issues Working Group. London: DCMS.

Department for Culture Media and Sport (DCMS) (2001). Creative Industries Mapping Document. London: DCMS

Florida, R. (2002a): Bohemia and economic geography. Journal of Economic Geography, 2, $1,55-71$.
Florida, R. (2002b): The Rise of the Creative Class. New York: Basic Books.

Florida, R. and Gates, G. (2001): Technology and Tolerance: The Importance of Diversity to High-Technology Growth. Washington, DC Centre on Urban \& Metropolitan Policy, The Brookings Institution.

Gertler, M., Florida, R., Gates, G. and Vinodrai, T. (2002). Competing on Creativity: Placing Ontario's Cities in North American Context. A report prepared for the Ontario Ministry of Enterprise, Opportunity and Innovation and the Institute for Competitiveness and Prosperity. Munk Centre for International Studies, University of Toronto.

Haapala, P. (2005). History of Tampere: the very long road to informational city. In: A. Kasvio and A.-V. Anttiroiko (Eds.) e-City. Analysing efforts to generate local dynamism in the city of Tampere. Tampere: Tampere University Press.

Hall, P. (2000). 'Creative Cities and Economic Development'. Urban Studies 37 (4) pp. 639-649.

Hietala, M and M. Kaarninen (2005). The foundation of an information city - education and culture in the development of Tampere. In: A. Kasvio and A.-V. Anttiroiko (Eds.) e-City. Analysing efforts to generate local dynamism in the city of Tampere. Tampere: Tampere University Press.

Hudson, R. (1998). 'Restructuring Region and State: The Case Of North East England'. Tijdshrift Voor Economische En Sociale Geografie 89(1): 15-30.

Jones, J. and Wren, C. (2004). 'Inward Foreign Direct Investment and Employment: A Project-Based Analysis In North East England'. Journal Of Economic Geography 4(5): 517-543.

Kostiainen, J. and M. Sotarauta (2002). Finnish city reinvented: Tampere's path from industrial to knowledge economy. Special Working Paper Series on Local Innovation Systems, MIT-IPC-LIS-02-002. Massachusetts Institute of Technology, Industrial Performance Center.

Lavanga, M. (2006a) Cities and Culture. Policies for a sustainable urban development based on culture. PhD Dissertation. Milan: IULM University.

McGuigan, J. (1996). Culture and The Public Sphere. London, Routledge.

Malvern, J. (2003). 'Cities play to gallery'. The Times 3 June, 18.

Miles, S. (2005). 'Our Tyne: Iconic Regeneration and The Revitalisation Of Identity In Newcastlegateshead'. Urban Studies 42(5/6): 913-926.
Nathan, M. (2005). The Wrong Stuff. Creative Class Theory, Diversity and City Performance. Discussion Paper no.1 Centre for Cities. London.

Northern Film \& Media (2004), 'The moving image sector in the North East of England: mapping, benchmarking and economic impact report': Report commissioned to Pembridge Partnership Limited.

Oakley, Kate (2004), 'Not So Cool Britannia: The Role of the Creative Industries in Economic Development' International Journal of Cultural Studies, 7:1, pp.67-77.

Peck, J. (2005). 'Struggling with the creative class.' International Journal of Urban and Regional Research, 29, 740-770.

Phillipson, J., Lowe, P. and Carrol, T. (2002). Confronting The Rural Shutdown: Foot and Mouth Disease and The North East Rural Economy. Newcastle Upon Tyne, Centre For Rural Economy, University Of Newcastle Upon Tyne.

Pike, A., Rodriguez-Pose, A. and Tomaney, J. (2006). Local and Regional Development. London, Routledge.

Porter, M.E. (1998). Competitive advantage: creating and sustaining superior performance: with a new introduction. New York: Free Press.

Pratt, A. (1997). 'The Cultural Industries Production System: A Case Study of Employment Change in Britain 1984-1991'. Environment and Planning A 29, pp.1953-1974.

Pratt, A. (2004). 'Creative clusters and Networks: toward a critical practice'. Media International Australia: culture and policy, 112 pp.50-66.

Russo, A.P., J. van der Borg and M. Lavanga (2005) The Impacts of Culture on the Economic Development of Cities. Final Report. Rotterdam: Euricur.

Scott, A.J. (2006). Creative cities: conceptual issues and policy questions. Journal of Urban Affairs, 28 (1): 1-17.

Scott, A.J. (2000). The Cultural Economy of Cities. Essays on the Geography of Image-Producing Industries. London: Sage Publications.

Sotarauta, M. and J. Kostianen (2005). Organising for futures in the city-region of Tampere: network management and the enabling development model. In: A. Kasvio and A.-V. Anttiroiko (Eds.) e-City. Analysing efforts to generate local dynamism in the city of Tampere. Tampere: Tampere University Press.

Turok, I. (2003). 'Cities, Clusters and Creative Industries: the Case of Film and Television in Scotland'. European Planning Studies 21, pp. 549-565.

Zukin, S. (1995). The Culture of Cities. Oxford, Blackwell. 


\section{RESEARCH NOTES: FDI AND POST-COMMUNIST HUNGARIAN INDUSTRIAL DEVELOPMENT}

\section{Eva Kiss, Geographical Research Institute, Hungarian Academy of Sciences}

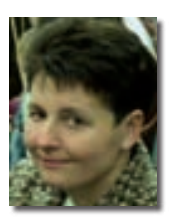
Introduction

In the last decades, there have been significant changes in the world economy. It has become more globalised and the spatial pattern of economic activity (or production) has also changed. There was a global shift in the world economy, which meant on one hand that production has been shifted from core economies to the periphery. On the other hand, it has not just been the volumes of invested capital which has increased but the direction of the international capital flows have also shifted. As a consequence of changes in the political system after 1989 , post-socialist countries have also become an attractive target for foreign investors, and this part of Europe has undergone a significant economic transformation.

After 1989 radical changes in the nature of organisation, structure and ownership have taken place in Hungarian industry, and these have had profound effects on the spatial pattern of industry. Foreign direct investment (FDI) and transnational companies (TNCs) have played a significant role in the transformation of the spatial organisation of the Hungarian economy inherited from socialist system. In this paper, I explore the restructuring which has already taken place, and consider what can be expected in the future.

\section{FDI as a significant force for change}

From 1989 to 2006, the total volume of investment into post socialist countries has totalled more than $\$ 300 \mathrm{bn}$; of this, Hungary has attracted around one-sixth of the total, or $\$ 50 \mathrm{bn}$. In the beginning of the 1990s, Hungary was in the lead of attracting foreign capital, because social and economic reforms were carried out faster and Hungary was a more open country than the other East Central European countries (Table 1.)

In Hungary the annual volumes of FDI have shown a great fluctuation, especially in the early years of economic transition, depending on many factors, and in particular on what was privatised in that particular year. What was consistent in this period was the fact that annually

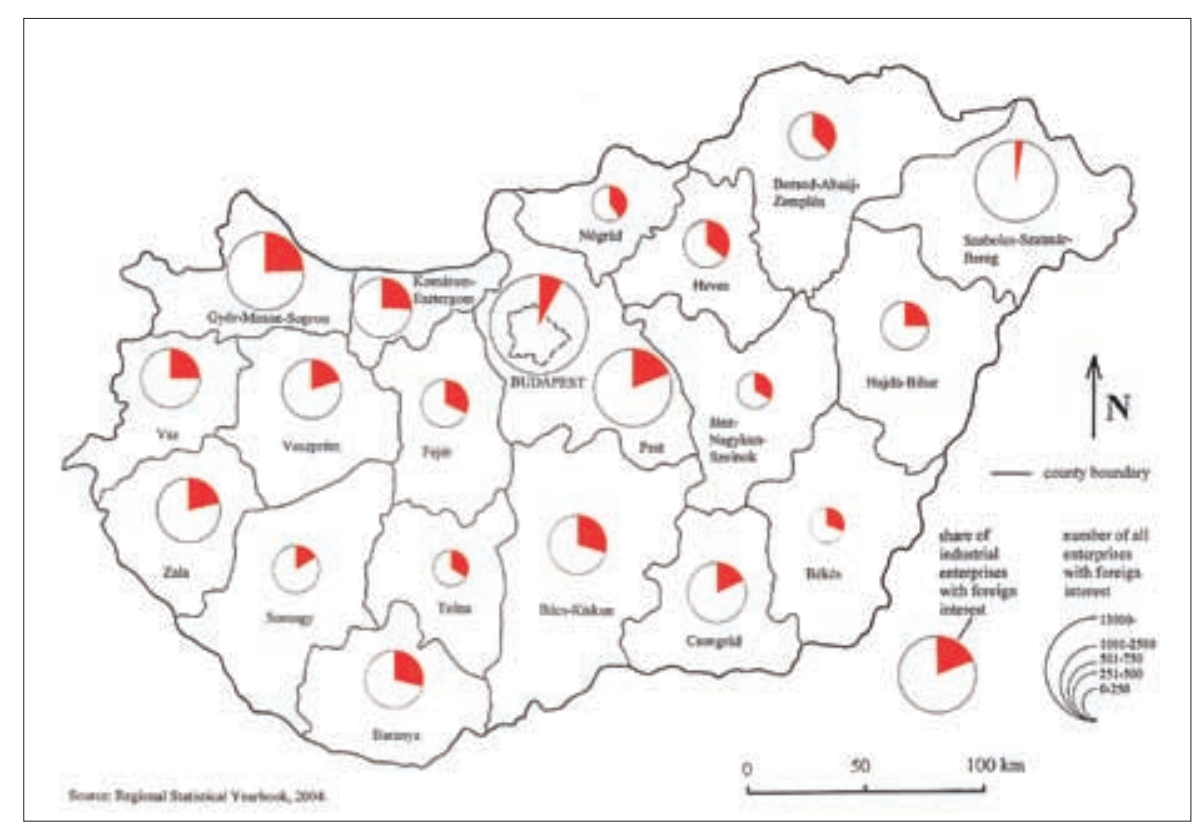

Figure 1: The location and importance of FDI by region

about $40-50 \%$ of all foreign capital were invested into industry (primarily into manufacturing), which is the most attractive sector for foreign investors.

It may perhaps surprise some readers to discover that it has been legally possible to establish businesses with a foreign interest in Hungary since 1972, but in reality their number began to increase only after 1989, peaking at the start of the 1990s. In 2005 there were almost 25,000 enterprises registering a foreign interest in Hungary, of which less than 3,500 operated in industry (mainly manufacturing). In comparison, other sectors, such as retail trade, there were over ten thousand businesses with a foreign interest. What is notable about FDI into manufacturing activity was that the

\section{Box 1: National differences in the types of investment made.} The most important investors were Germany, The Netherlands, Austria and USA These four countries account for $60-70 \%$ of the invested capital in Hungary, and this ranking has not changed during last decade. Investors from each of these countries have a particular spatial preference, which has remained constant since 1989.

Germans and Austrians have mainly invested in the northern part of Transdanubia (including Győr-Moson-Sopron, Vas, Zala, Komárom-Esztergom, Fejér, Veszprém counties) and in the Central Hungary Region (Budapest and Pest county). The Dutch have primarily chosen investment locations in the Northern Great Plain Region (Szabolcs-Szatmár-Bereg, Hajdú-Bihar, Jász-Nagykun-Szolnok counties), while American investors established their enterprises all over the country.

National distinctions can also be made in the nature of individual investments, besides their locations. Whilst German and Austrian investors have made smaller investments in much larger numbers, American investments, although fewer in number, have tended to be larger and more strategic. 
motives), electronics chemicals, food and the textile industry. The picture has not changed since 1998, although there has been a steady increase in the number of investors.

\section{The new industrial geography of FDI}

There has been a clear spatial element to the arrival of FDI in the post-socialist period; there has been an opening-up of the North West of the country to inward investment, as pioneer firms have created a familiar environment for the later investments. It is possible to distinguish two key areas of interest to foreign investors in Hungary.

One of them is Budapest and its wider vicinity. Almost $40 \%$ of FDI-backed enterprises were established in the Central Hungarian Region, despite the fact that the economy here is going through a decline in the importance of manufacturing, driven by restructuring in the Hungarian owned sector along with the fast development of service sector.

The other most attractive region for

\begin{tabular}{|c|c|c|c|c|c|c|}
\hline Host region/economy & 1985 & 1990 & 1995 & 2000 & 2001 & 2005 \\
\hline World & 913.1 & 1871.5 & 2911.7 & 6258.3 & 6845.7 & 10129.7 \\
\hline Developed economies & 568.6 & 1383.0 & 2021.3 & 4.124 .2 & 4504.1 & 7117.1 \\
\hline Developing economies & 344.4 & 484.954 & 849.9 & 2002.1 & 2181.2 & 2756.9 \\
\hline Central/ East Europe & 0.049 & 3.6 & 40.5 & 131.8 & 160.3 & 470.6 \\
\hline Albania & - & - & 0.211 & 0.578 & 0.759 & 1.6 \\
\hline Belarus & - & - & 0.050 & 1.2 & 1.41 & 2.3 \\
\hline Bosnia-Herzegovina & - & .1 & 0.021 & 0.355 & 0.5 & 2.0 \\
\hline Bulgaria & - & - & 0.445 & 3.1 & 3.8 & 9.1 \\
\hline Croatia & - & - & 0.473 & 5.1 & 6.5 & 12.5 \\
\hline Czech Republic & - & 1.3 & 7.3 & 21.6 & 26.7 & 59.4 \\
\hline Estonia & - & - & 0.674 & 2.6 & 3.1 & 12.2 \\
\hline Hungary & 0.049 & 0.569 & 11.9 & 19.8 & 23.5 & 61.2 \\
\hline Latvia & - & - & 0.615 & 21.0 & 2.2 & 4.7 \\
\hline Lithuania & - & - & 0.352 & 2.3 & 2.6 & 6.4 \\
\hline Moldova & - & - & 0.093 & 0.459 & 0.6 & 1.1 \\
\hline Poland & - & 0.109 & 7.8 & 33.6 & 42.4 & 93.3 \\
\hline Romania & - & 0.766 & 1.1 & 6.5 & 7.6 & 23.8 \\
\hline Russia & - & - & 5.4 & 19.2 & 21.7 & 132.4 \\
\hline Slovakia & - & 0.081 & 0.8 & 4.6 & 6.1 & 15.3 \\
\hline Slovenia & - & 0.665 & 1.7 & 2.8 & 3.2 & 8.0 \\
\hline Macedonia & - & - & 0.033 & 0.4 & 0.9 & 1.88 \\
\hline Ukraine & - & - & 0.910 & 3.8 & 4.6 & 17.2 \\
\hline Serbia and Montenegro & - & - & 0.329 & 1.3 & 1.4 & 5.4 \\
\hline
\end{tabular}

foreign investors is the northern part of Transdanubia. This region is home to $28 \%$ of businesses established through regions, as figure 1 above shows, account for the lion's share of all investment by volume and share. foreign investment. FDI in these two

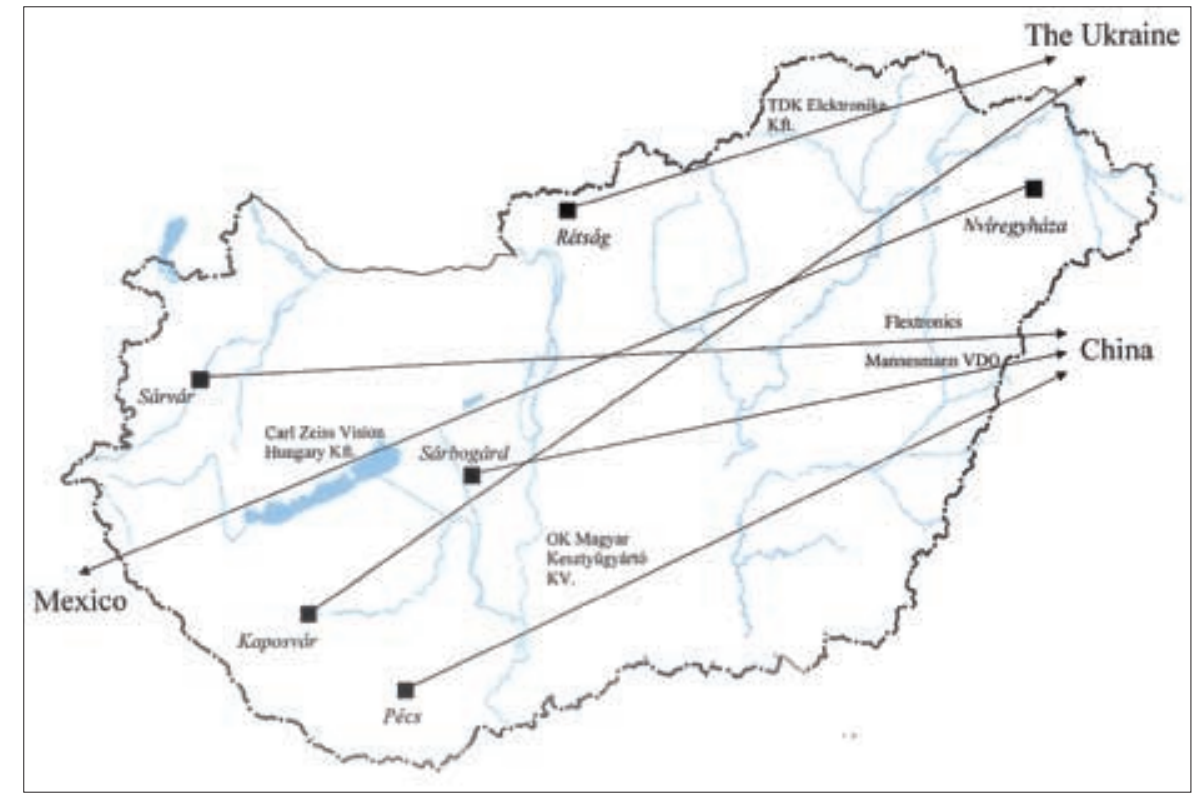

Figure 2: Relocations from Hungary to low cost locations

Why are these regions so attractive for foreign investors? It is possible to distinguish a number of important factors:

- Proximity to the western border

- Good transport linkages

- Skilled labour force (with language skills)

- Better quality of living and urban fabric

- Well developed industrial infrastructure

- Avoided a crisis immediately after socialism

- Returning emigrants used to Austrian and German labour practices.

\section{The future for Hungarian manufacturing?}

Now the question is that how this new spatial pattern of industrial production will change in the future. Of course there are many factors which will affect the ultimate outcome, but perhaps the most salient issue facing Hungary at the moment is relocation. In common with countries across Europe, Hungary faces pressure from low cost countries. Indeed, in the last years, it has become increasingly common within the Hungarian media to hear the story that TNCs are considering leaving the country to move further east. The issue for Hungary is the threat that this poses for undermining the gains to the industrial structure since 1989.

Despite a perception of a threat from lower cost locations, my data has revealed that in reality there have only been a few cases of relocation from Hungary. First a German company, Mannesmann, moved from Hungary to China in 2000, 
Box 2: From the geography of the socialist to the post-socialist These most attractive regions for foreign investors can be regarded as forming a new industrial district of Hungary, which was evident in its current form by the second half of the 1990s. After 1989, Hungarian industrial space has undergone significant changes in which foreign investment has played a dominant role. The socialist economic geography was based on the location of natural resources, mineral and energy sources, and followed a northeast-southwest axis. As a consequence of FDI, a new northwest-southeast axis has been produced. This new industrial region is now the main focus for industrial production. This region is about one-third of the country's area, where almost $70 \%$ of FDI is concentrated, and $80 \%$ of investment in industries in this new district is of foreign origin (see Figure 3 below).

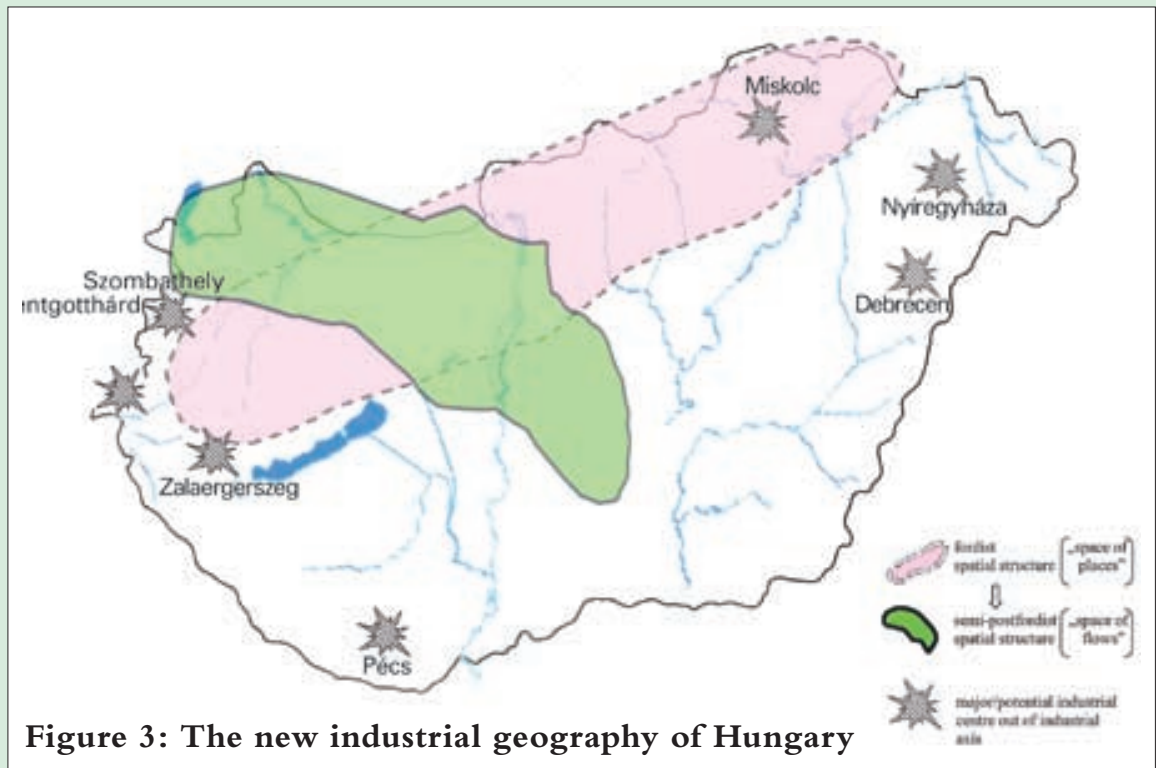

The new industrial district can be regarded as the 'winner' of the change in the system, whilst others part of the country, especially the northeast, where a continuing crisis within traditional heavy industrial sectors has caused a serious problem, belongs to the row of 'losers'. Indeed, it is hard to determine whether it is their poor image which has dissuaded investors from choosing these regions, or their poor image is a result of negative investment decisions by foreign investors.

and later others followed it. When this happened for the first time, it was a real shock for the local society, as local residents were not accustomed to the idea that these foreign companies had not set-

tled down forever, and were constantly on the look-out for better conditions, lower costs and more pliant workforces. The realization process was very painful, particularly in the beginning.

Although by now relocation is very common in global terms, in Hungary there were only a few firms which relocated. Despite a concern for the potential negative impacts of this development, it remains true to say that the volume of net investment remains broadly positive, and FDI remains a driver behind this new industrial geography - the northwest-southeast axis.

The experience of relocation highlights the extent to which FDI in its entirety was a new phenomenon for Hungary, in common with other post-socialist countries. There was no sense at the beginning of transition that it would profoundly alter the productive structure of the country beyond correcting the inefficiencies of socialist arrangements. Despite this, foreign direct investment has played a very important role in the shaping of the new industrial space, and foreign capital flows are still important today.

To date relocation has not had a great impact on the new spatial pattern of industry, which suggests that the new industrial pattern is likely to persist in the short run, in any case. However, in the long run, anything can happen: only one thing is sure; given the extent of foreign ownership of the Hungarian productive structure, FDI will plan a significant role in determining the future pattern of Hungary's manufacturing economy.

Prof. Eva Kiss is a Research
Fellow at the Hungarian Academy
for Social Sciences in Budapest,
Hungary. This article reports
research on the spatial restructuring
of the Hungarian economy through
foreign direct investment (project
number T046014).

\section{NEW MEMBERS}

\section{ASSOCIATE}

Sven Illeris, Roskilde University, Denmark

Georges de Veirman, Brussels, Belgium

\section{CORPORATE}

Chris Anderson, Government Office North East, Newcastle

Vanessa Curry, Yorkshire \& Humber Assembly, Wakefield

\section{HONORARY}

Andrew Morrison, London

\section{INDIVIDUAL}

Larissa Davies, Sheffield

Theodore Papaioannou,

Open University

Koen Frenken, Utrecht University,

Netherlands

Irene Martinez, Pisa, Italy

Fabrizio Guzzo, Cosenza, Italy

E. Fekete, Miskolc, Hungary

Gediminas Macys, Kaunas, Lithuania
Nicolae Boar, Romania

Elena Porumb, Cluj, Romania

Diogo Abreu, Alameda de Universidade Lisbon, Portugal

Rui Joao Velez dos Santos Camelo, Lisbon, Portugal

Nicola Underdown, Nottingham

Pedro Costa, Lisbon, Portugal

Jacques Fache, Nantes, France

Peter Kresl, Pennsylvania, USA

Simon Pemberton, Liverpool

David Morris, DTZ Pieda Consulting, Manchester

Roger Morfey, London

Agata Maida, Turin, Italy

Stefanie Duhr, Radboud University Nijmegen, Netherlands

Marie-Antoinette Maupertuis, University of Corsica Corte, France

Eduardo Beira, Portugal

Florence Bell, Carlisle
Jose Lucio, Lisbon, Portugal

Caroline Chapain, University of Birmingham

STUDENT

Joseph Alan Charlton, Durham

Nickolina Fuduric, Aalborg University,

Denmark

E. Tranos, Newcastle University

Slavomir Ondos, Comenius University of Bratislava, Slovenia

Benjamin Gore, University

of Westminster

Martina Romanova, Prague, Czech Republic

Helle Kristensen, Aalborg University,

Denmark

Adela Nistor, Indiana, USA

Sonia Fernandes, Lisbon, Portugal

Pedro Matos, Lisbon, Portugal

Alice Mah, Oxford

Andres Ulloa, Facultad de Economia, Chile

Ahmad Sadaqa, Ramallah, Palestine 


\section{NEWS AND REVIEWS}

Some colleagues told me how interesting and inspiring the recent RSA International Conference in Lisbon was. Unfortunately, I could not make it due to teaching and research obligations. But in the summer I hope to spend some weeks in the Mediterranean and enjoy the atmosphere there. I am sure you are also looking forward to the summer holiday. Perhaps you even have time then to read the books that are still lying on your desk. If you have such a book and if you want to review it, please don't hesitate to contact me at g.j.hospers@utwente.nl. In this 'News \& Reviews', Pawel Capik reviews a recent book on clusters and regional development. Besides his piece, you will find a 'call for papers' for one of the coming issues of Regions and an 'event report' on the conference Paul and I organised in my hometown.

Happy reading and enjoy the summer!!

Gert-Jan Hospers University of Twente

\section{CALL FOR PAPERS FOR REGIONAL SURVEY ON REGIONAL BRANDING}

More and more regions invest in their 'branding' to attract new inhabitants, visitors and companies. 'Oresund - the Human Capital', 'The North East - Passionate People, Passionate Places', 'Umbria The Green Heart of Italy' are telling examples of such 'place branding'. Regions invites scholars and practitioners to submit short contributions of about 1500 words that improve our understanding of place branding and its contribution to regional development. We particularly welcome short pieces from masters/doctoral students and early career researchers, and are available to help with finalizing pieces if necessary.

Submissions may include theoretical and empirical studies, and deal with regional case studies, best and/or worst practices of regional branding, the contribution of culture to a place brand, possible branding strategies, regions and their appearance in the media, the (missing) link between regional identity, image and brand, critical remarks towards place branding, etc. The deadline for submissions is 15 th October 2007, for publication in Regions 269 (Spring 2008).
For questions, contact guest editor Gert-Jan Hospers (g.j.hospers@utwente.nl).

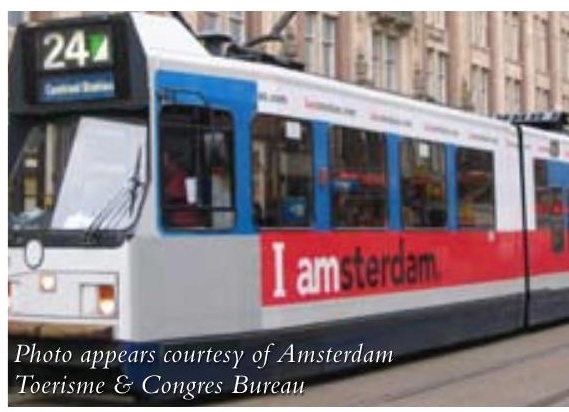

\section{EVENT REPORT: THE ROLE OF CULTURE IN THE ECONOMIC DEVELOPMENT OF OLD INDUSTRIAL REGIONS}

\section{3rd Annual meeting of the RSA 'Old Industrial Knowledges' working group, University of Twente, Enschede, Netherlands, 28th-30th January 2007}

Following successful conferences in Newcastle and Gdánsk, the RSA 'Old Industrial Knowledges' working group recently gathered in Enschede, the Netherlands, to continue ongoing discussions surrounding the economic development of old industrial regions. Led by Paul Benneworth and Gert-Jan Hospers, this 3rd annual conference focused on the increasingly important role that culture is playing in the economic development of old industrial regions.

Located in the east of the Netherlands, Enschede was an apt choice for hosting this third conference, given that the town and the wider region of Twente had experienced widespread socioeconomic decline as its textile-based industrial structure was dis- mantled through processes of deindustrialisation during the twentieth century. Similar to many more familiar industrial regions, Enschede experienced rapid industrialisation during the nineteenth century based primarily on the textile industry.

This experience even led Enschede to be referred to as the Manchester of the Netherlands. Indeed, over the next three days, a recurring theme of our conference was the identification of old industrial regions

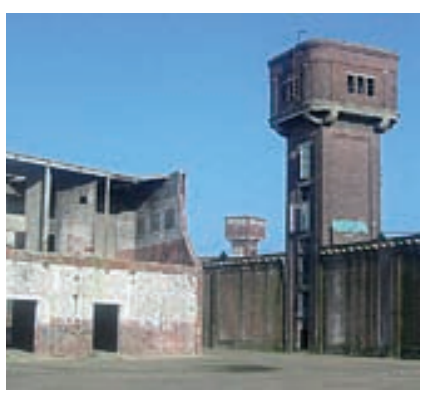

across Europe as the Manchester of Poland, the Manchester of Russia, and so on.

Like many other industrial regions, it was during the second half of the twentieth century that Enschede's fortunes changed with the onset of deindustrialisation as what was left of the textile industry relocated to the Far East. As we walked around the town on the first day of our conference, the landscape and architecture is hardly recognisable from the strong industrial heritage that we are told about, with the redevelopment of Roombeek providing a powerful illustration of the capacity for redevelopment in old industrial region.

Following our trip around Enschede, we took a train across the border into Germany to look at how the development of the Gronau 'Rock \& Pop' museum has provided cultureled regeneration to another old industrial town. Funded by the federal state, this national project had aspired to the culture-led regeneration experienced in Bilbao. A selected quarter of the town was redeveloped in the hope that this would stimulate further investment into the surrounding town. Both experiences provided a strong stimulus for the main part of the conference.

Drawing on research undertaken in various old industrial regions across ten countries, 24 presentations were heard over the ensuing two days. With the aim of exploring the role of culture in the economic development of old industrial regions, the driving force behind the conference's theme was the recognition that 
culture is more and more the business of cities, and has been latched on to by old industrial regions because culture has been seen as critical to the emergence of a post-industrial knowledge society.

Over the two days, one of the clearest messages to emerge from the conference was the hegemonic status afforded to the ideas and concepts of Richard Florida by policymakers and local leaders within old industrial regions. Despite most delegates acknowledging Florida's thesis on the rise of the creative class, the underlying tone of the conference reflected the broad scepticism that is afforded towards Florida within the academy.

The issue, as we discovered, was that while we can all voice our opinions on the merits of Florida's work, the lack of an alternative thesis suggests that policymakers within old industrial regions will continue to be fixated by the concept of the creative class, and our academic work will also continue to be situated within the Florida model of post-industrial economic development.

Alongside the work of Florida, many papers stressed the importance of high-end cultural events that offer international branding for old industrial regions. More commonly referred to as the 'Bilbao-effect', a strong theme of the conference was the importance placed by old industrial regions on international events such as Expo and European Capital of Culture, alongside state-led national programmes of cultural identity and branding.

Indeed, the conference offered a useful comparison between old industrial regions that have been successful with culture-led regeneration through international events such as these (Lisbon, Essen, Manchester, Liverpool) and those which had either been unsuccessful or had adopted different approaches to culturally branding their city (Newcastle, Gdánsk).

Finally, a concern amongst the conference delegates was the lack of an accurate definition for what constitutes cultural industries. It was clear from the presentations that culture led regeneration can be taken in any number of ways, and indeed the conference theme uncovered a number of critical questions that remain ripe for ongoing discussion:

- Who should get the value from cultural development - residents or tourists?

- Should culture-led regeneration focus on participatory or representative programmes? - Should old industrial regions chase after high-end international investment through awards such as European Capital of Culture or focus more on facilitating locally inspired and organically occurring forms of culture? - What spatial approach should culture-led regeneration adopt in old industrial regions to develop the periphery as well as the core (and how does this affect the spatial geography of old industrial regions)?

- How should culture-led regeneration in these old industrial regions balance out the need for short-term funded projects and long-term transformational programmes?

To draw these issues together, the conference concluded that the relationship between culture and urban planning in old industrial regions is an evolving research agenda for scholars from a range of disciplinary backgrounds. Indeed, the conference has once more provided the stimulus for ongoing research to continue through the 'Old Industrial Knowledges' working group.

Dr John Harrison

Loughborough University

\section{BOOK REVIEW}

\section{Asheim, B., Cooke, P. \& Martin, R. (2006) (Eds.), Clusters and regional development: critical reflections and explorations, London: Routledge, ISBN 0-414-34914-1. Reviewed by Pawel Capik, Centre for Contemporary European Studies, University of Paisley.}

'Clusters represent a new way of thinking about national, state and local economies and they necessitate new roles for companies, government and other institutions in enhancing competitiveness' (Porter 2000, p.16) Do they? This short question offers a minimalist summary of a recent book in the Routledge and RSA - Regions and Cities series, entitled 'Clusters and Regional Development: Critical Reflections and Explorations', edited by Bjørn Asheim, Philip Cooke and Ron Martin. The book comes after over a decade of chiefly uncritical academic and policy tributes paid to the notion of clusters.

Based on the principle offered earlier by Martin and
Sunley (2003), the mere popularity of the cluster concept is by no means a guarantee of its profundity. From the outset, the book identifies the main inconsistencies in the cluster theory: the lack of criteria for identification or even approximation of cluster boundaries; the lack of clarity in causal relations between innovation, productivity and competitiveness; and limited empirical evidence of various kinds of interlinkages.

However, those who expect to find a explicit argument against clusters will be disappointed, as this collection of papers instead aims to provide a definitive account of the notion, as a conceptual framework, an empirical construct and a policy tool. The central concern of the volume is to offer a theoretically driven critical appraisal of the cluster concept - its attractions, as well as its weaknesses and limitations.

The fourteen essays comprising the volume can be generally divided into two broad groups: those that criticise the cluster notion on the whole, and those that dispute its individual aspects and attempt to contribute to its development. The introductory chapter, authored by the book editors, sets the scene for the parts that follow. It initially explores the origin of the cluster concept by going back to Marshall's notion of industrial districts. Then it unveils the consecutive developments leading to the recent 'cluster craze' (p.1).

By doing so it offers perspectives on how clusters should be conceptualised. Further, by weighting the advantages against the flaws of the concept, the authors argue the whole idea has been oversold. As often is the case in public policy, the swift application of the cluster notion to development policy on various levels has not been preceded by many theoretical, conceptual and empirical explorations.

One such theoretical systematisation is offered in the next essay, in which Maskell and Kebir attempt to present systematic answers to questions 
not only of 'what?', 'why?' and 'how?', but also of 'when?', 'where?', and 'who?' By analysing some commonly used approaches, the authors find differences in theory constituting elements, followed by dissimilar policy recommendations.

In respond to this, in the next part Malmberg and Power, discussing the elusive nature of the cluster concept, suggest dropping the cluster puritanism and argue for greater conceptual flexibility. The chapter attempts to determine if clusters are primarily functional or spatial phenomenon, and how that affects knowledge creation and innovation, a theme that recurs in latter parts of the volume.

Next Belussi indicates the various strands of research (including new economic geography, evolutionary economics and innovation studies) and then tries to pull them together by reviewing Marshall's 'industrial districts' and Porter's 'clusters' notion and indicating similarities in their evolution and characteristics.

In a consecutive essay (the book's longest chapter), Pannicia 'cuts through the chaos' of various approaches, definitions and interpretations within the cluster notion. The author offers a typology of industrial districts underpinned by the relationship between proximity and efficiency, flexibility, innovation, growth and cooperation.

The description of the six distinguished types that follows falls somewhat short of providing policy implications. 'We know a great deal about the characteristics and functioning of mature industrial clusters such as Silicon Valley and Route 128 in Boston', Feldman and Francis argue in the subsequent essay.

From the policy perspective, however, it is critically important to know 'how a cluster is started in a region that previously would not be characterised as innovative' (p.129). In response to this query the authors offer a "theory of entrepreneurial-driven cluster formation and growth', and discuss it within the framework of a cluster life cycle.

In the subsequent chapter on cluster evolution, Nooteboom scrutinises the local context of innovation and argues that clusters sometimes inhibit rather than foster innovative behaviour. In these circumstances public policy, 'if viable at all', should switch from designing clusters to facilitating their development, 'as a function of local conditions in "giving a nudge here and there", to yield triggers or remove obstacles' (p.160). There is enough evidence to suggest that not clustering but innovation enhances competitiveness and exports. Therefore, one of the primary matters that most of the cluster critique is based on is that of causality.

In one of the book's best chapters, halfway through the volume, Simmie addresses the question of whether clustering is a cause or effect of competitiveness. While engaging in a discussion with Porter's ideas, the author summarises concerns surrounding the cluster notion expressed in various chapters throughout the book. By the time the readers reach the conclusions, they may find themselves doubting the innovative character of cluster theory, for Simmie with - the help of well chosen examples has unambiguously indicated how agglomeration economies determines co-location, and how established export-base theories explain why places require export to grow.

After such a stark, well presented case against clusters, the part comes that is possibly least critical of the notion. The successive two essays from an institutional perspective explore the role of clusters in knowledge creation and diffusion. Audretsch and Lehmann provide insight into institutional factors endogenous to the entrepreneurial firm impeding the knowledge spillovers. Steiner asks 'do clusters think', and asserts that clusters are coordinating institutions for knowledge-sharing, organisational learning and management of new technologies.

Knowledge flows, albeit in a different perspective, are further explored by Gertler and Wolfe. Using original research (a long awaited exception rather than a norm for the book) the authors explain the relative importance of local and non-local actors, relationships, and forces in the development of innovative forms of production.

The following chapter offers a rather unorthodox perspective on Hollywood. Scott examines the local labour market and explores ways in which its collective participants operations can enhance the overall competitiveness of industrial clusters. Cluster boundaries are the most fundamental issue for cluster identification but also for conceptual soundness of the concept.

Swann partially addresses the question of cluster size and its boundaries, but more interestingly asks the unpopular question of fate of places outside the cluster. Such environments face costs associated with growing volumes of transport, and further, corresponding to the core-periphery concept, hinterlands are drained by clusters of their resources, which additionally impedes their development chances.

The final essay of the volume is decisively conclusive in nature as it addresses one of the book's and indeed clusters' main uncertainties, i.e. what is the added value from the cluster notion? Henry, Pollard and Benneworth, in line with some earlier contributions, argue that "clusters should be understood as a set of multiple perspectives each of which encompasses a conceptual underpinning and methodological approach' (p.272).

There are certain issues always associated with edited volumes, coherence, repetitions and contradictions, being among the more important ones. While many parts cohere, and rather dispute then contradict one another, numerous repetitions could have been avoided (notably reoccurring theme of the cluster concept's genesis), which would release space for more illustrations, including maps, graphs and diagrams, of which the majority of essays are seriously lacking.

An undoubted advantage of the volume lies with the vast literature that has been reviewed, contributing in most parts to the soundness of the theoretical argument. The dominance of theoretical parts is purposeful. However, empirical evidence, specifically from untraditional places beyond the western economies, could strengthen the reliability of the hypothetical discussion.

In short, Clusters and Regional Development: Critical Reflections and Explorations' is certainly a timely (and long awaited) contribution to the slowly emerging discussion on the omnipotence of the notion of clusters. It is one of those rare books that should be judged by its cover, as it does exactly what it says on the tin.

IN THE NEXT
ISSUE....
- Scotland's future in the
UK?
- City-regions as
intelligent territories?
- A new instrument
for cross-border
co-operation
Regions 267 is published at
the end of September 2007




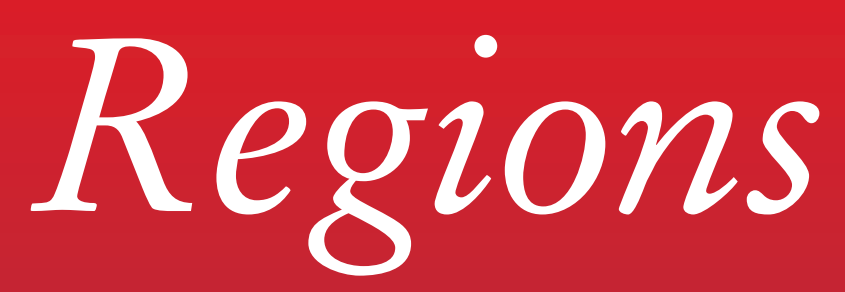

The VoICE OF THE MeMBERSHIP

In this Regional Survey, we discuss the extent to which culture can contribute to the economic development of Europe's old industrial areas, on the basis of the third meeting of the RSA working group on on Old Industrial Knowledges, held at the University of Twente, 29th-31st January 2007. The first five papers deal with the experiences with culture in old industrial places in the United Kingdom. Clifton and Cooke show that the creative class in England and Wales consistent with Florida's theory is concentrated in diverse, bohemian, socially cohesive and culturally vibrant places.

Four English case studies follow. Carole Chapain uses a case study of Birmingham to suggest a tailor-made approach to stimulating the cultural economy. John Harrison deals with England's North West and the choice for Liverpool as the European Capital of Culture 2008. Roberta Comunian shows that public support might have both positive and negative effects on local cultural development, using the case of Newcastle-Gateshead. Jon Swords argues that there is also potential for the cultural heritage cluster in regenerating the economy.

The final two papers in the special issue deal with Finland and Poland. Mariangela Lavanga shows how the Finnish industrial city of Tampere developed from a 'Manchester of the North' via an e-city towards a cultural city. Grzegorz Micek reports on the Polish IT industries, where education and embeddedness are more important than cluster development per se.

The common thread is culture which can indeed play a role in regenerating the economy of old industrial regions. It is not just mere numbers of jobs that count, but rather the new image created by culture to regions seeking a new economic future. However, there is more than high-brow-culture; popular culture also contributes to local economic development.

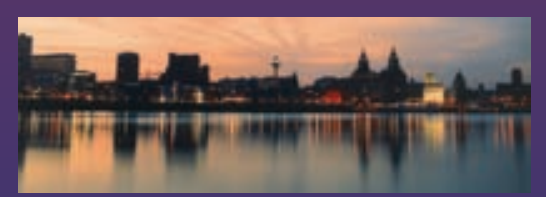

Regional Studies Association,PO Box 2058, Seaford, East Sussex BN25 4QU, UK

Tel: 0044 (0)1323 899 698, Fax: 0044 (0)1323 899798

rsa@mailbox.ulcc.ac.uk, www.regional-studies-assoc.ac.uk

Registered Charity No: 1084165

Registered Company, Limited By Guarantee In England No: 4116288 